\title{
Integrated Guidance on the Care of \\ Familial Hypercholesterolaemia from the International FH Foundation
}

Gerald F. Watts ${ }^{1}$, Samuel Gidding ${ }^{2}$, Anthony S. Wierzbicki ${ }^{3}$, Peter P. Toth ${ }^{4}$, Rodrigo Alonso ${ }^{5}$, W. Virgil Brown ${ }^{6}$, Eric Bruckert ${ }^{7}$, Joep Defesche ${ }^{8}$, Khoo Kah Lin $^{9}$, Michael Livingston ${ }^{10}$, Pedro Mata ${ }^{11}$, Klaus G Parhofer ${ }^{12}$, Frederick J. Raal $^{13}$, Raul D. Santos ${ }^{14}$, Eric J. G. Sijbrands ${ }^{15}$, William G. Simpson ${ }^{16}$, David R. Sullivan ${ }^{17}$, Andrey V. Susekov ${ }^{18}$, Brian Tomlinson ${ }^{19}$, Albert Wiegman ${ }^{20}$, Shizuya Yamashita ${ }^{21}$, John J. P. Kastelein ${ }^{22}$.

${ }^{1}$ Cardiometabolic Service, Department of Internal Medicine, Royal Perth Hospital, School of Medicine and Pharmacology, University of Western Australia;

${ }^{2}$ Cardiology Division, Nemours Cardiac Nemours Cardiac Center, A. I. duPont Hospital for Children, Wilmington, Delaware, and Jefferson Medical College, Philadelphia, Pennsylvania, US;

${ }^{3}$ Department of Metabolic Medicine and Chemical Pathology, Guy's \& St Thomas Hospitals, NHS Foundation Trust, London, UK;

${ }^{4} \mathrm{CGH}$ Medical Centre, Sterling, Illinois, University of Illinois College of Medicine, Peoria, and Illinois Michigan State University College of Osteopathic Medicine, East Lansing Michigan, US;

${ }^{5}$ Lipid Clinic, Department of Internal Medicine, Fundacion Jimenez Diaz, Madrid, Spain;

${ }^{6}$ Emory University School of Medicine, Emory University, Atlanta, Georgia, US;

${ }^{7}$ Department of Endocrinology and Prevention of Cardiovascular Disease, Hôpital Pitié-Salpêtrière, University of Paris VI, Paris, France;

${ }^{8}$ Laboratory for Experimental Vascular Medicine, Section of Molecular

Diagnostics, Academic Medical Centre, University of Amsterdam, The

Netherlands;

${ }^{9}$ Pontai Medical Centre, Heart Foundation of Malaysia, Kuala Lumpur,

Malaysia;

${ }^{10}$ The International FH Foundation, St Andrews Court, Thame, Oxfordshire, UK;

${ }^{11}$ Fundacion Hipercolesterolemia Familiar, Madrid, Spain;

${ }^{12}$ Medical Department 2, Division of Metabolism and Endocrinology, LudwigMaximilians-University of Munich, Munich, Germany;

${ }^{13}$ Carbohydrate and Lipid Metabolism Research Unit, Faculty of Health Sciences, University of the Witwatersrand, Johannesburg, South Africa;

${ }^{14}$ Lipid Clinic Heart Institute (InCor), University of Sao Paulo Medical School, University of Sao Paulo, Brazil;

${ }^{15}$ Section of Pharmacology, Vascular and Metabolic Diseases, Department of Internal Medicine, Erasmus Medical Center, Erasmus University, Rotterdam, The Netherlands;

${ }^{16}$ Department of Clinical Biochemistry, Aberdeen Royal Infirmary, University of Aberdeen, Aberdeen, Scotland; 
${ }^{17}$ Lipid Clinic and Department of Biochemistry, Royal Prince Alfred Hospital, University of Sydney, New South Wales, Australia;

${ }^{18}$ Laboratory of Clinical Lipidology, Department of Atherosclerosis, Cardiology

Research Complex, Ministry of Health of Russian Federation, Moscow,

Russia;

${ }^{19}$ Division of Clinical Pharmacology, Department of Medicine and

Therapeutics, The Chinese University of Hong Kong, Prince of Wales

Hospital, Hong Kong SAR, The People's Republic of China;

${ }^{20}$ Department of Paediatrics, Academic Medical Centre, University of Amsterdam, The Netherlands;

${ }^{21}$ Departments of Community Medicine and Cardiovascular Medicine, Osaka University Graduate School of Medicine, Osaka University, Japan;

${ }^{22}$ Department of Vascular Medicine, Academic Medical Centre, University of Amsterdam, The Netherlands.

\section{Addressee for correspondence:}

Professor Gerald F. Watts, Cardiometabolic Services, Department of Internal Medicine, Royal Perth Hospital, School of Medicine and Pharmacology, The University of Western Australia; GPO Box X2213 Perth WA 6847.

Tel: ++ 619224 0245; Fax: ++ 619224 0246;

E-mail: gerald.watts@uwa.edu.au 
Familial hypercholesterolaemia $(\mathrm{FH})$ is a dominantly inherited disorder present from birth that markedly elevates plasma low-density lipoprotein (LDL) cholesterol and causes premature coronary heart disease. There are at least 20 million people with $\mathrm{FH}$ worldwide, but the majority remains undetected and current treatment is often suboptimal.

To address this major gap in coronary prevention we present, from an international perspective, consensus-based guidance on the care of $\mathrm{FH}$. The guidance was generated from seminars and workshops held at an international symposium. The recommendations focus on the detection, diagnosis, assessment and management of $\mathrm{FH}$ in adults and children, and set guidelines for clinical purposes. They also refer to best practice for cascade screening and risk notifying and testing families for $\mathrm{FH}$, including use of genetic testing. Guidance on treatment is based on risk stratification, management of non-cholesterol risk factors and safe and effective use of LDL lowering therapies. Recommendations are given on lipoprotein apheresis. The use of emerging therapies for $\mathrm{FH}$ is also foreshadowed.

This international guidance acknowledges evidence gaps, but aims to make the best use of contemporary practice and technology to achieve the best outcomes for the care of $\mathrm{FH}$. It should accordingly be employed to inform clinical judgment and be adjusted for country-specific and local healthcare needs and resources.

Key Words: familial hypercholesterolaemia, international guidance, adults, children, screening, diagnosis, assessment, treatment, models of care. 


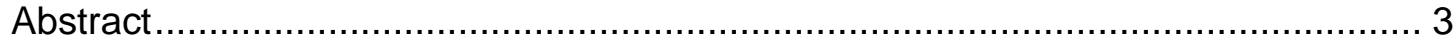

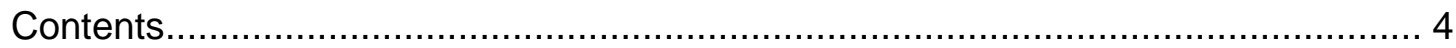

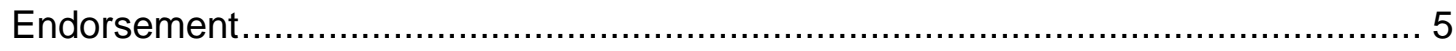

Abbreviations and Conversion Factors ............................................................. 5

Levels of Evidence and Grades of Recommendation ......................................... 6

Summary of Recommendations ..................................................................... 7

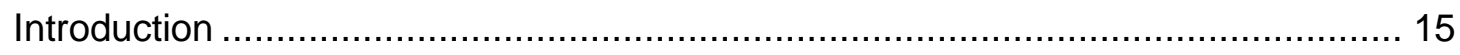

Detection of Index Cases: Screening for $\mathrm{FH}$...................................................... 16

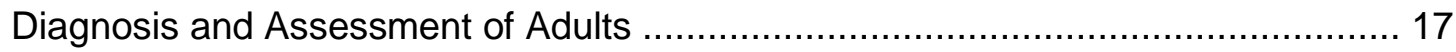

Diagnosis and Assessment of Children and Adolescents .................................. 21

Cascade Screening: Risk Notification of Families............................................... 24

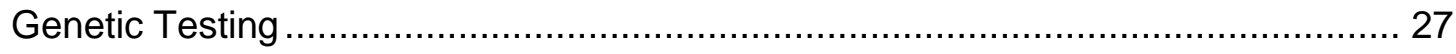

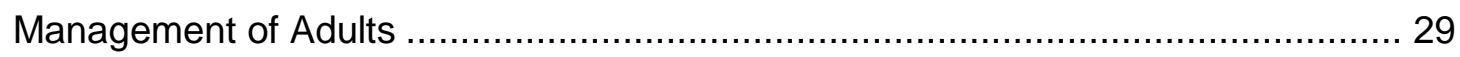

Management of Children and Adolescents ................................................... 37

Lipoprotein apheresis and other invasive therapies ......................................... 40

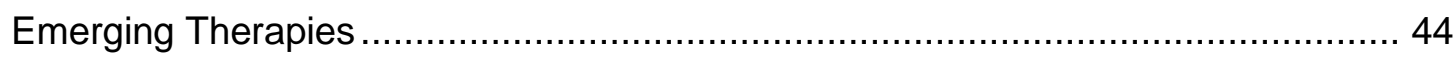

Organization and Development of Care ........................................................... 48

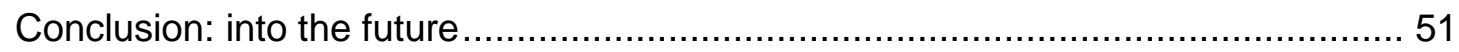

Author Contributions and Consensus Process .................................................. 53

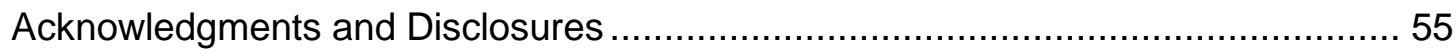

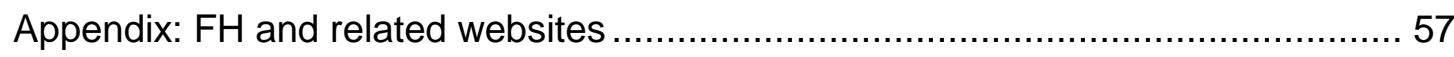

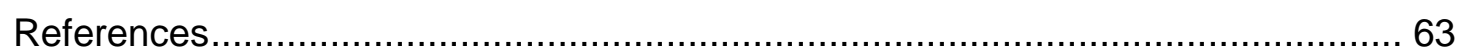


The recommendations contained in this document have been fully endorsed by The National Lipid Association, 6816 Southpoint Parkway (Suite 1000), Jacksonville, FL3316, US.

\section{Abbreviations and Conversion Factors}

Abbreviations:

ApoB, apolipoprotein B-100; CAC, coronary artery calcification; CHD, coronary heart disease; $\mathrm{CK}$, creatine kinase; CIMT, carotid intima-medial thickness; CT, computerized tomography; CVD, cardiovascular disease; DLCNC, Dutch Lipid Clinic Network Criteria; DLCNS, Dutch Lipid Clinic Network Score; DRG, Diagnosis-Related Groups; FDA, Food and Drug Administration; $\mathrm{FH}$, familial hypercholesterolaemia: GP, general practitioner; HDL, high-density lipoprotein; ICD, International Classification of Diseases; LA, lipoprotein apheresis; LDL, low-density lipoprotein; LDLR, low-density lipoprotein receptor; $L p(a)$, Lipoprotein (a); Mabs, monoclonal antibodies; MEDPED, Make Early Diagnosis to Prevent Early Death; MHT, menopausal hormone therapy; MPLA, Multiplex Ligation Probe Amplification; MTP, microsomal triglyceride transfer protein; PCSK9, proprotein convertase subtilisin-like kexin Type 9; REMS, Risk Evaluation Mitigation Strategy; VLDL, very low-density lipoprotein.

\section{Conversion Factors:}

$\mathrm{mg} / \mathrm{dL}$ cholesterol $=\mathrm{mmol} / \mathrm{L} \times 38.7 ; \mathrm{mg} / \mathrm{dL}$ triglyceride $=\mathrm{mmol} / \mathrm{L} \times 88.6 ; \mathrm{mg} / \mathrm{dL}$ lipoprotein $(\mathrm{a})=0.0357 \mu \mathrm{mol} / \mathrm{L}$. 


\section{Levels of Evidence:}

$1=$ systematic review/meta-analysis/at least one randomised control trial/good quality diagnostic tests.

2 = good quality clinical or observational studies.

3 = expert opinion or clinical experience/argument from first principles.

(The evidence for therapeutic interventions was considered principally in respect of effects on plasma LDL-cholesterol concentrations, but where available was also based on data on subclinical atherosclerosis or cardiovascular outcomes.)

\section{Grades of Recommendation:}

$A=$ can be trusted to guide practice .

$\mathrm{B}=$ can be trusted to guide practice in most situations.

$\mathrm{C}=$ can be used to guide practice, but care should be taken in application . 


\section{Summary of Recommendations}

\section{Detection of Index cases: Screening and Phenotypic Diagnosis}

1.1 Targeted, opportunistic and universal screening strategies should be employed to detect index cases [2B].

1.2 Index cases should be sought by targeted screening of adults with premature cardiovascular disease (CVD), primarily coronary heart disease (CHD) and a personal and/or family history of hypercholesterolaemia. [1A ]

1.3 Opportunistic screening of adults and children in primary care, based on age- and gender-specific plasma LDL-cholesterol levels, should be routinely adopted. [2B] 1.4 Universal screening based on age- and gender- specific plasma LDL-cholesterol levels should be considered prior to age 20 years and ideally before puberty. [2C] 1.5 In adults, country-specific clinical tools, such as the Dutch Lipid Clinic Network, Simon Broome, MED-PED or Japanese FH criteria, may be used to make a phenotypic diagnosis. [1A]

1.6 The effect of acute illness and concurrent use of statins in lowering plasma LDLcholesterol must be considered: testing for $\mathrm{FH}$ should not be carried out during acute illness; LDL-cholesterol level should be appropriately adjusted in people on statins, particularly if a reliable pre-treatment value is not available [2A]

1.7 All patients with suspected FH should be referred to a clinic specialising in lipidology and/or metabolic disorders for further assessment, if such a service is available. [3A]

\section{Diagnosis and Assessment of Adults}

2.1 Secondary causes of hypercholesterolaemia should first be excluded. [1 A] 2.2 The most reliable diagnosis of $\mathrm{FH}$ can be made using both phenotypic (see $\mathbf{1 . 5}$ above and 4.8 below) criteria and genetic testing, but when genetic testing is not available the diagnosis can be made phenotypically. [1A]

2.3 DNA testing increases the accuracy of detecting $\mathrm{FH}$ and, if resources permit, should be considered to confirm the diagnosis, especially if cascade screening is planned; a fully accredited laboratory should be used. [1 A]

2.4 Although $\mathrm{FH}$ is a life-time coronary risk equivalent, patients should be assessed for additional major cardiovascular risk factors, including lipoprotein(a) [Lp(a)], the level of hypercholesterolaemia at diagnosis and the prematurity of the family 
(especially first-degree relatives) or personal history of CVD. Framingham or other cardiovascular risk equations should not be used. [2A]

2.5 The presence of additional cardiovascular risk factors should guide the intensity of medical management. [2A]

2.6 Cardiovascular imaging (eg. cardiac computed tomography and carotid ultrasonography) may be useful for assessing asymptomatic patients, but its value is not fully established. [2C]

\section{Diagnosis and Assessment of Children and Adolescents}

3.1 Secondary causes of hypercholesterolaemia should first be excluded. [1A]

3.2 With the exceptions noted in 3.3, children should be genetically tested for $\mathrm{FH}$ only after a pathogenic variant (mutation) has been identified in a parent or first degree relative. [1 $\mathbf{A}]$

3.3 Children may initially be genetically tested for $\mathrm{FH}$ when parents or first degree relatives are unknown or deceased, or as an accepted screening practice in certain countries, such as the Netherlands [3B]

3.4 Age-, gender- and country -specific plasma LDL-cholesterol concentration thresholds should be used to make the phenotypic diagnosis; because of biological variation, two fasting LDL-cholesterol values are recommended.[1B]

3.5 A plasma LDL-cholesterol of $5.0 \mathrm{mmol} / \mathrm{L}$ or above indicates high probability of $\mathrm{FH}$ in the absence of a positive parental history of hypercholesterolaemia or premature $\mathrm{CHD}$; an LDL-cholesterol of $4.0 \mathrm{mmol} / \mathrm{L}$ or above indicates high probability of $\mathrm{FH}$ in the presence of a positive parental history of hypercholesterolaemia or premature CHD [1B]

3.6 Patients should be risk stratified according to age, presence of other cardiovascular risk factors, family history of early onset CVD (especially in firstdegree relatives) and the level of LDL-cholesterol at diagnosis. [2A]

3.7 The presence of additional cardiovascular risk factors, and hence risk stratification, should guide the intensity of medical management. [3A]

3.8 Carotid ultrasonography may be employed to assess risk, but its value is not fully established; it should only be carried out in centres with specific expertise. [2C]

3.9 Cardiac CT should not be used routinely to assess patients with heterozygous FH. [3A] 


\section{Cascade Screening: Testing and Risk Notification of Families}

4.1 Notification of relatives at risk of FH should generally not be carried out without the consent of the index case. [3A]

4.2 Relatives should only be directly notified of their risk without consent of the index case if there is specific legislative provision for breach of confidentiality in the relevant jurisdiction. [3C]

4.3 A proactive approach that respects the principles of privacy, justice and autonomy is required. [3A]

4.4 Pre-testing counselling should be offered to at risk family members of an index case prior to any form of testing. [1 A]

4.5 Systematic cascade screening should ideally be co-ordinated by a dedicated centre and should not be carried out in primary care without central co-ordination, particularly if employing DNA testing. [1B]

4.6 Cascade screening of families should be carried out using both a phenotypic and genotypic strategy, but if DNA testing is not available a phenotypic strategy alone should be used [1 A]

4.7 Cascade screening should initially be carried out as a priority in first-degree relatives and then extended to second- and third-degree relatives. [1 A]

4.8 In the absence of genetic testing, the diagnosis of $\mathrm{FH}$ should be made in close relatives using age- , gender- and country- specific plasma LDL-cholesterol levels. Diagnostic clinical tools for index cases, such as the Dutch Lipid Clinic Network and Simon Broome criteria, should not be employed to make the diagnosis of $\mathrm{FH}$ in relatives [1A]

4.9 DNA testing makes cascade screening more cost-effective and should be employed to screen family members after the mutation is identified in the index case. [1A]

4.10 Children with xanthomata or other physical findings of homozygous $\mathrm{FH}$, or at risk of homozygous FH should be screened as early as possible and definitely by 2 years of age. [2A]

4.11 Children with suspected heterozygous $\mathrm{FH}$ should be screened between the ages of 5 and 10 years; age at screening should be similar in boys and girls. [ 2B]

\section{Genetic Testing}

5.1 Genetic testing for FH should ideally be offered to all 'index cases' who have a phenotypic diagnosis of $\mathrm{FH}$. [3A] 
5.2 When the phenotypic diagnosis of FH is unlikely (e.g. by Dutch Lipid Clinic Network Criteria), genetic testing of the 'index case' need not be carried out. [1C] 5.3 Genetic testing for $\mathrm{FH}$ must be carried out in an accredited laboratory using standardised methods that target specific mutations and/or by exon-by-exon sequencing. [1 A]

$\mathbf{5 . 4}$ If genetic testing detects a variant, its significance as a pathogenic mutation, a previously reported variant of uncertain significance, a novel variant of uncertain significance or a benign (normal) variant needs to be assessed and recorded. [1 A] 5.5 If genetic testing does not detect a variant, $\mathrm{FH}$ due to undetected mutations or mutations in untested genes cannot be excluded, particularly if the clinical phenotype is strongly suggestive of $\mathrm{FH}$. [1 A]

\section{Management of Adults}

6.1 All adult patients with $\mathrm{FH}$ must receive advice on lifestyle modifications and advice to correct all non-cholesterol risk factors should be provided according to expert recommendations. [2A]

6.2 Therapy should ideally aim for at least a $50 \%$ reduction in plasma LDLcholesterol, followed by an LDL-cholesterol $<2.5 \mathrm{mmol} / \mathrm{L}$ (absence of $\mathrm{CHD}$ or other major risk factors) and $<1.8 \mathrm{mmol} / \mathrm{L}$ (presence of $\mathrm{CHD}$ or other major risk factors). [2C]

6.3 Achieving these targets will require a fat-modified, heart-healthy diet and statin therapy with or without ezetimibe. [1A]

6.4 Drug combinations including bile acid sequestrants, niacin, probucol or fibrates, may be required with more intensive strategies to further reduce LDL-cholesterol. [1B]

6.5 Plasma levels of hepatic aminotransferases, creatine kinase, glucose and creatinine should be measured before starting drug therapy. All patients on statins should have hepatic aminotransferases monitored; creatine kinase should be measured when musculoskeletal symptoms are reported; glucose should be monitored when there are risk factors for diabetes. [2A]

6.6 All women of child-bearing age should receive pre-pregnancy counselling, with appropriate advice on contraception, before starting a statin and this should be reinforced at annual review. [2A]

6.7 Statins and other systemically absorbed lipid regulating drugs should be discontinued 3 months before planned conception, as well as during pregnancy and breast feeding. [2A] 
6.8 Although carotid ultrasonography has been used in clinical trials, its role in monitoring therapy as part of the clinical care for $\mathrm{FH}$ has not been established and it should therefore not be used at present for this purpose. [3C]

6.9 Lomitapide and Mipomersen should be considered as adjunctive treatments to diet and cholesterol lowering drugs in adults with homozygous $\mathrm{FH}$ to further reduce plasma LDL-cholesterol, particularly if lipoprotein apheresis is not available. [1C]

6.10 Well controlled and low complexity patients should be followed-up in primary care, whereas higher complexity patients will need regular review by a specialist, with the option of shared care. Review intervals should vary according to clinical context. Opportunities should be created for integrating the primary and specialist care of $\mathrm{FH}$. [3B]

\section{Management of Children and Adolescents}

7.1 Patients must receive advice on lifestyle modifications and on correcting noncholesterol risk factors; primordial prevention (counselling to inhibit the development of risk factors) is particularly important. [2A]

7.2 To lower elevated plasma LDL-cholesterol in this age group generally requires a fat-modified, heart-healthy diet and a statin, with the possible addition of ezetimibe or a bile acid sequestrant. [1 $\mathrm{A}]$

7.3 All patients should be treated with diet, with statins considered at age 8 to 10 years and ideally started before age of 18 years; plasma LDL-cholesterol targets in this age group need not be as intense as for adults [2B]

7.4 Boys and girls should generally be treated at similar ages, although with a particularly adverse family history of CHD and other major risk factors, boys with heterozygous $\mathrm{FH}$ could be considered for earlier treatment with statins. [2B]

7.5 Children, between the ages of 8 and 10 years, with proven $\mathrm{FH}$ on a suitable diet and LDL-cholesterol $>4.0 \mathrm{mmol} / \mathrm{L}$ on two occasions should be started on low-dose statin monotherapy, aiming for an LDL-cholesterol $<4.0 \mathrm{mmol} / \mathrm{L}$.[3C]

7.6 After the age of 10 years, children with proven $\mathrm{FH}$ on a suitable diet and LDLcholesterol $>3.5 \mathrm{mmol} / \mathrm{L}$ on two occasions should be started on statin monotherapy, aiming for an LDL-cholesterol $<3.5 \mathrm{mmol} / \mathrm{L}$, with the addition of ezetimibe or a bile acid sequestrant if required. [3C]

7.7 The preferred statins for initiating therapy are those that are licensed for clinical use in this age group in specific countries; other statins may be prescribed according to clinical indications, higher doses of potent statins being required in homozygotes. [1C] 
7.8 Although statins can be safely used in children, weight, growth, physical and sexual development, and well-being should be monitored in this age group. [1 A] 7.9 Plasma levels of hepatic aminotransferases, creatine kinase, glucose and creatinine should be measured before starting drug therapy. All patients on statins should have hepatic aminotransferases monitored; creatine kinase should be measured and compared to pre-treatment levels when musculoskeletal symptoms are reported; glucose should be monitored if there are risk factors for diabetes. [2A] 7.10 All adolescent girls should receive pre-pregnancy counselling, with appropriate advice on contraception, before starting a statin and this should be reinforced at annual review. [3A].

7.11 Although carotid ultrasonography has been used in clinical trials, its role in monitoring therapy in patients with heterozygous $\mathrm{FH}$ has not been established and it should therefore not be used for this purpose. [3C]

7.12 Well controlled and lower complexity patients should be followed up in primary care, whereas higher complexity patients will need regular review by a paediatrician. Opportunities should be created for integrated care between GPs and paediatricians. Family based and transitional care clinics should be considered by adult and paediatric services. [3B]

7.13 Children with homozygous $\mathrm{FH}$ should be referred on diagnosis to a specialist centre and drug and/or apheresis treatment commenced as soon as possible. [2A] $\mathbf{7 . 1 4}$ In children with homozygous $\mathrm{FH}$ and rapidly progressive atherosclerosis, Lomitapide and Mipomersen, although not yet tested in children, should be considered, employing special access or compassionate use schemes, as adjunctive treatments to diet and conventional drugs to further reduce plasma LDL-cholesterol, particularly if apheresis is not available or declined by the patient/family. [3C]

\section{Lipoprotein apheresis and related treatments}

8.1 Lipoprotein apheresis (LA) should be considered in all patients with homozygous or compound heterozygous $\mathrm{FH}$ (i.e. homozygous $\mathrm{FH}$ phenotype) and carried out in a dedicated centre with the relevant expertise. [1A]

8.2 LA should be considered in patients with heterozygous $\mathrm{FH}$ with $\mathrm{CHD}$ who cannot achieve LDL-cholesterol targets despite maximal drug therapy or because they cannot tolerate statins. [2A]

8.3 LA should be considered in children with homozygous $\mathrm{FH}$ by the age of 5 and no later than 8 years. [2A] 
8.4 Diet and drug therapy to lower LDL-cholesterol should be continued during treatment with LA [2A].

8.5 The efficacy, tolerability and safety of LA must be regularly reviewed. [3A]

8.6 The effect of LA on progression of atherosclerosis should be monitored according to clinical indications in $\mathrm{FH}$ patients with echocardiography (aortic valve and root), carotid ultrasonography and exercise stress testing. [3B]

8.7 Lomitapide should be considered as an adjunctive to standard diet and drug therapy to further lower plasma LDL-cholesterol in adults with homozygous $\mathrm{FH}$ on LA. [1C]

8.8 Lomitapide should be considered, via a special access scheme, as an adjunctive treatment to further lower plasma LDL-cholesterol in children and adolescents with homozygous $\mathrm{FH}$ on LA with rapidly progressive atherosclerosis. [3C]

8.9 Mipomersen should be considered as an adjunctive to standard diet and drug therapy to further lower plasma LDL-cholesterol in adults, children and adolescents with homozygous $\mathrm{FH}$ on LA who cannot tolerate lomitapide. [3C]

$\mathbf{8 . 1 0}$ If available, orthotopic liver transplantation should be considered for younger patients with homozygous $\mathrm{FH}$ who have rapid progression of atherosclerosis or aortic stenosis, cannot tolerate LA or when plasma LDL-cholesterol cannot be adequately lowered with $L A$, diet and drug treatment. [3B]

\section{Organization and Development of Care}

9.1 Care pathways for FH should be developed for country-specific and local needs. [3A]

9.2 Specialist services should be multidisciplinary based and integrated with primary care. [3B]

9.3 Specialist care of FH should ideally be supported by cardiology, paediatric, genetic, imaging, transfusion medicine, nursing, dietetic, psychology, pharmacy and pathology laboratory services. [3A]

9.4 Cascade screening should ideally be centrally co-ordinated by a dedicated centre. [1 A]

9.5 Low complexity patients should be managed in primary care, with the option of annual specialist review. [3A]

9.6 Higher complexity patients should be managed principally in specialist centres.

9.7 Medical, nursing and allied health staff managing patients with $\mathrm{FH}$ should be accredited in cardiovascular prevention. [3A] 
9.8 Services should establish partnerships with academic and professional organizations to enhance teaching, training and research. [3A]

9.9 A registry of patients and families should be established for clinical, research and audit purposes. [3A]

9.10 A support group of patients and families should be established as a major priority for enhancing public, government and health care provider awareness, as well as the total quality of care of $\mathrm{FH}$. [3A] 
Familial hypercholesterolaemia $(\mathrm{FH})$ is the most common dominantly inherited disorder in man [1]. FH is most frequently due to dominant, loss of function mutations in genes affecting the low-density lipoprotein $(L D L)$ receptor that clears LDL particles from plasma [2], and therefore LDL-cholesterol levels is markedly elevated from birth. FH accelerates atherosclerotic cardiovascular disease (CVD), especially coronary heart disease (CHD), with clinical manifestations often occurring after one to four decades of life $[3,4]$. Screening allows early detection of individuals [5-9], thereby allowing use of preventive interventions including lifestyle measures, cholesterol-lowering medications and management of other CVD risk factors [6-16]. There are probably more than 15 million people with $\mathrm{FH}$ worldwide, but less than $10 \%$ have been detected and only $5 \%$ adequately treated $[3,4,17,18]$.

To address this major gap in coronary prevention, the International FH Foundation facilitated a series of discussions with experts to develop harmonized guidance for the care of FH. Formal presentations and informal discussions took place at the XVI International Symposium on Atherosclerosis (Sydney, 2012) in workshops that addressed evidence for treatment, screening and DNA testing, paediatric management, novel therapies, health economics, regional diversity in management, and models of care. Workshop moderators identified and collated consensus based on published research, clinical experience, common themes, expert opinion, and other international guidelines on FH [6-9, 19-22]. To supplement this process a brief 
questionnaire on potentially contentious issues in $\mathrm{FH}$ (screening options, DNA testing, risk stratification, testing and treatment of children, use of imaging, and therapeutic targets) was then completed by a selected group of international experts, with the majority view employed to inform further consensus. This international guidance presents a standard of care for $\mathrm{FH}$ patients within in a framework that can be adjusted for country-specific, regional and local requirements, and within which future evidence and consensus may be developed [23].

\section{Detection of Index Cases: Screening for FH}

A systematic strategy for detecting index cases (i.e. first individuals diagnosed in families) of $\mathrm{FH}$ is essential [6-9]. The index case is the trigger for cascade screening, whereby new cases can be efficiently discovered [3, 8, 9]. Both screening methods need to be well integrated in models of care [8]. Universal screening prior to age 20 years and ideally before puberty, based on age- and gender-specific plasma LDL-cholesterol levels, should also be considered if feasible [9, 21]. However, experience concerning its use and implementation is very limited. From a population perspective, universal and cascade screening methods for FH should be closely integrated [24]. The success of all detection strategies will depend on adequately addressing several barriers, including population awareness of $\mathrm{FH}$ and family, physician and societal concerns of the value of screening for $\mathrm{FH}$.

Potential index cases of FH should be sought amongst patients aged less than 60 years with CVD presenting to coronary care, stroke, cardiothoracic 
and vascular units $[8,25]$, as well as amongst similar patients attending cardiac rehabilitation programs. The greatest yield will be from screening younger adult patients with $\mathrm{CHD}[25,26]$. A coronary event in a family member can increase the perception of risk and the willingness of relatives to be subsequently tested for $\mathrm{FH}$. Screening in primary care should employ an initial non-fasting lipid profile [8], which should be undertaken opportunistically, based on family history of hypercholesterolaemia and premature CVD (age < 60 years) [27, 28]. FH screening should also be offered to all patients with tendon xanthomata and premature arcus cornealis $[6-9,22]$. All forms of opportunistic screening should account for the effect of any acute illness in lowering plasma total and LDL-cholesterol $[28,29]$, in which case lipid testing should be delayed or repeated at least 8 weeks after recovery. There is a role for community laboratories alerting primary care physicians about $\mathrm{FH}$ on the basis of a high plasma LDL-cholesterol ( eg > 5 $\mathrm{mmol} / \mathrm{L}$ ) or high total cholesterol (e.g. $>7 \mathrm{mmol} / \mathrm{L}$ ) [30]. When feasible, all patients with suspected $\mathrm{FH}$ should be referred to a specialist with expertise in

$\mathrm{FH}$ for confirmation of the diagnosis [26, 28, 31]. All patients with homozygous $\mathrm{FH}$ (untreated LDL-cholesterol > $13 \mathrm{mmol} / \mathrm{L}$; treated LDL-cholesterol $>7.5$ $\mathrm{mmol} / \mathrm{L}$ ) [32] must be referred to the nearest specialist centre for management $[8,31,33]$.

\section{Diagnosis and Assessment of Adults}

There are a number of criteria for diagnosing $\mathrm{FH}$ phenotypically in adults, but none are internationally agreed $[6-9,22]$. The Dutch Lipid Clinic Network Criteria (DLCNC) are used to calculate a numerical score predicting the 
probability of the diagnosis of $\mathrm{FH}$ [34]. These criteria are increasingly accepted as simple and comprehensive $[8,13,34]$; the numerical score is not highly dependent on the plasma level of LDL-cholesterol and can be more sensitive in detecting index cases, with a score $>5$ making the diagnosis highly probable. The Simon Broome system is comparable to the DLCNC in predicting an $\mathrm{FH}$ mutation, but does not employ arcus cornealis and may also overlook patients with true $\mathrm{FH}$ who are not overtly hypercholesterolaemic. The MEDPED System, which relies on plasma total and LDL-cholesterol and strictly requires that cholesterol measurements be first known in other family members [35], may also be less specific in predicting mutations than other methods. The Japanese criteria, which are comparable to the Simon Broome system, employ a population-specific LDL-cholesterol $>4.7 \mathrm{mmol} / \mathrm{L}$ and allow for a radiographic diagnosis of Achilles tendon xanthomata [22]. Further international research is required to establish simple and harmonised criteria for the clinical diagnosis of $\mathrm{FH}$.

The diagnosis of $\mathrm{FH}$ should be based on at least two fasting measures of plasma LDL-cholesterol $[8,10,13]$. Obtaining the family history of $\mathrm{CHD}$ and hypercholesterolaemia is important to enhance the phenotypic diagnosis [6, $26,34-36]$, but this information is often neglected or may not be available in practice $[25,37]$. The presence of tendon xanthomata in early life with marked elevation in plasma LDL-cholesterol establishes the diagnosis of severe $\mathrm{FH}$ [32], but sitosterolaemia should also be excluded with plasma phytosterol and DNA testing [38]; in adults, tendon xanthomata with normal plasma cholesterol may be seen in sitosterolaemia and cerebrotendinous 
xanthomatosis. Secondary causes of hypercholesterolaemia (e.g. hypothyroidism, proteinuria, medications) must be excluded $[8,13,22]$, but the clinical stigmata of $\mathrm{FH}$ do not occur in these conditions. LDL-cholesterol is underestimated by the Friedewald equation if the plasma triglyceride level is > $4.5 \mathrm{mmol} / \mathrm{L}$ [28], when a direct LDL-cholesterol assay should be employed. The levels of apoB and non-HDL-cholesterol (i.e. total cholesterol minus HDLcholesterol) for diagnosing $\mathrm{FH}$ have not been defined. $\mathrm{FH}$ must be distinguished from familial combined hyperlipidaemia [22, 39], a multigenic disorder with a variable lipid phenotype that co-expresses with insulin resistance and does not exhibit tendon xanthomata. Significant hypertriglyceridaemia makes the diagnosis of $\mathrm{FH}$ less likely, but may rarely be seen with co-existing genetic defects in lipoprotein metabolism [40, 41]. For patients on cholesterol lowering medication, pre-treatment LDL-cholesterol values must be obtained or interpolated from the drug type and regimen used [42].

All patients diagnosed with $\mathrm{FH}$ should be investigated for other CVD risk factors $[8,22,43,44]$ and the presence of symptomatic or subclinical atherosclerosis $[7,8,45]$. Assessment must take account of the psychological, intellectual, social and ethnic status of the patient $[46,47]$. Detailed and culturally appropriate exploration of the individual's family history of CVD, particularly among first-degree relatives, is essential. Risk of CVD amongst patients with $\mathrm{FH}$ can vary widely $[43,44]$. This may relate to the pre-treatment plasma level of cholesterol, genetic causes affecting lipid metabolism or arterial biology, and the presence of other major risk factors, in particular 
smoking, obesity, low HDL-cholesterol, hypertension and diabetes [43, 44]. Mutations that very markedly elevate plasma LDL-cholesterol [48] and independently increase plasma $L p(a)$ concentrations also enhance the risk of CVD in FH [49]. Elevated $\mathrm{Lp}(\mathrm{a})$ may also contribute to the development of aortic stenosis [50]. Framingham Risk Scores, or scores derived from other cardiovascular risk engines, are not reliable to guide management in $\mathrm{FH}$ and should not be used $[8,10,11]$, particularly in younger patients, in whom a measure of long-term risk based on imaging of subclinical atherosclerosis may be more appropriate $[14,51,52]$. An assessment of cholesterol-life years, or cumulative cholesterol burden, may also be useful in risk assessment [53], but its value in managing individual patients requires evaluation.

$\mathrm{FH}$ is associated with early onset and increased burden of subclinical atherosclerosis [52, 53]. Certain measures of subclinical atherosclerosis have been independently associated with the onset of $\mathrm{CHD}$ in the general population $[54,55]$, but have been generally applied to $\mathrm{FH}$ in research settings alone and require further evaluation. Increased carotid intima-medial thickness (CIMT) and the presence of plaques may be assessed by carotid ultrasonography $[52,54,56]$. Coronary artery calcification (CAC) and luminal obstruction can be assessed with cardiac computed tomography/angiography $[45,54,57]$. In asymptomatic individuals, CAC score may be superior to CT coronary angiography in risk prediction [58], and more clinically useful than CIMT [59]. Non-invasive testing for atherosclerosis could be useful in the assessment and management of $\mathrm{FH}$, but this is not established. Testing could be individualized to specific clinical situations [57, 60], being particularly useful 
when the family history of CVD is unclear [61]. Subclinical atherosclerosis should be defined according to recognized criteria [54]. Reference intervals for common CIMT have recently been reported [62], but have not been validated in $\mathrm{FH}$. Echocardiography for aortic stenosis may be indicated for heterozygous individuals with marked elevation in plasma $L p(a)$ concentration $[49,50]$, and as a routine investigation in homozygous $\mathrm{FH}$ to diagnose both aortic and/or supra-aortic valve disease [8, 32, 43-45, 63].

Given that CVD risk and the clinical expression is variable in $\mathrm{FH}$, it is reasonable to employ some form of risk stratification. Subdivision into lower, (absence of CHD, subclinical atherosclerosis and major risk factors) and higher (presence of CHD, subclinical alterations or major risk factors) risk can guide the intensity of medical management $[7,8]$. The cost-effectiveness of this therapeutic approach requires evaluation, however. Patients considered to have a homozygous FH phenotype should be classified at exceptionally high risk [32], and be referred to a specialist centre for consideration for lipoprotein apheresis [64] or trial of new therapies [8].

\section{Diagnosis and Assessment of Children and Adolescents}

$\mathrm{FH}$ should be identified in youth, certainly before 18 years of age and younger if indicated and feasible $[19-21,53,65,66]$. This is particularly important for those at risk for homozygous $\mathrm{FH}$, where recognition at about 2 years or even earlier is considered optimal [19-21, 53, 65, 66]. Sitosterolaemia may masquerade as homozygous $\mathrm{FH}$ in childhood and the diagnosis should be considered [38]. Boys and girls with potential heterozygous FH should also be 
screened before the age of 10 years, preferably between ages of 5 and 10 years. However, earlier screening may be justified with a family history of CHD prior to age 55 years, especially in first-degree relatives [63, 67, 68], or at the specific request of parents wishing to embed healthy lifestyle measures at a very early age. Detection of $\mathrm{FH}$ in childhood employing three strategies can be considered: cascade screening, universal screening, or selective screening based on family history $[21,27,66]$. Different countries will utilize different strategies based on health care resources and recommendations by local expert groups. In several European countries and Australia, cascade screening based on genetic testing has been advocated $[5,6,8,19]$, whereas in the United States selective screening beginning at age 2 years and universal screening at age 9-11 years has been advocated $[9,20]$. Universal screening by age 20 years, and ideally before puberty, is recommended; universal screening has been practised in Slovenia [21] and tested in some universities in Japan, but the yield and cost-effectiveness remain unclear. Universal screening of children, followed by child-parent testing may be a more effective approach to detecting $\mathrm{FH}$ in the population than cascade screening alone [24]. Importantly, none of the aforementioned paediatric screening strategies for $\mathrm{FH}$ have hitherto been validated for efficacy, riskbenefit and cost-effectiveness [69].

Age- and gender-specific plasma LDL-cholesterol concentration thresholds should be used to make an initial diagnosis of $\mathrm{FH}[67,70]$. Plasma LDL-cholesterol level alone has excellent discrimination between those with and without $\mathrm{FH}$ below the age of 10 years $[67,70,71]$. However, because of 
biological variation [29, 72], the average of at least two fasting LDL-cholesterol levels should be used to make the diagnosis of $\mathrm{FH}[19,20,65]$. The effects of acute illness in lowering LDL-cholesterol should be accounted for and tests repeated if necessary $[29,72]$. The diagnosis of heterozygous $\mathrm{FH}$ is highly likely in children over 2 years of age if the LDL-cholesterol level is greater or equal to $5 \mathrm{mmol} / \mathrm{L}[67,68]$, even in the absence of a family history of hyperlipidaemia and premature CHD. Heterozygous $\mathrm{FH}$ is also probable at untreated LDL-cholesterol levels between 4 and $5 \mathrm{mmol} / \mathrm{L}$, especially in the setting of a positive family history [67]. Homozygous FH should be considered if the untreated LDL cholesterol level is $>13 \mathrm{mmol} / \mathrm{L}$, especially if xanthomata are evident before age 10 years [19, 20, 32, 65, 73]. Secondary causes of hypercholesterolemia, including nephrotic syndrome and hypothyroidism, should be excluded before diagnosing $\mathrm{FH}[19,20,65]$.

As for adults, a complete CVD risk assessment including determination of blood pressure, body mass index, tobacco use, glucose and lipoprotein(a) should be performed $[19,20,65]$. The presence of these additional risk factors, or other high risk paediatric conditions, such as diabetes mellitus, Kawasaki disease with giant aneurysms or chronic kidney disease, may be an indication for intensification of lipid lowering treatment [73]. Eliciting a positive family of early CVD, especially among first-degree relatives $[63,67,68]$, is important for planning therapy.

Subclinical atherosclerosis imaging, using CIMT and assessment of CAC by CT scanning $[52,74]$, has been used in research settings to determine the presence of early atherosclerosis in children with $\mathrm{FH}$. Its 
practical value remains to be established, however. There are significant limitations to using subclinical atherosclerosis imaging to monitor treatment in clinical practice [54]. Measurement of CIMT requires special expertise [75]. The recently reported standardised reference intervals for common CIMT [62] excluded children.

There are also no accepted thresholds for defining the presence and progression of atherosclerosis in children by CIMT. CIMT measurements are highly age-dependent and poorly reproducible in young children, making assessment of change difficult [74]. Assessment of CAC is not recommended, since it may be absent in early atherosclerosis due to cholesterol-rich plaques, does not regularly develop until mature adulthood, and repeat CT scans increase the exposure to radiation [54].

\section{Cascade Screening: Risk Notification of Families}

The most cost-effective approach for detecting new cases of $\mathrm{FH}$ is family cascade screening of close relatives of a diagnosed index case using a phenotypic or genotypic strategy $[5,6,8,76,77]$. Diagnostic testing based on a pathogenic mutation is more accurate, however, than using the phenotype alone [78]. If a DNA testing service is not available, cascade screening should be carried out using age-, gender- and country-specific plasma LDLcholesterol levels alone [70]. Because of higher pre-test probability, clinical diagnostic tools for index cases should not be used for relatives. The drawing of a family pedigree can be valuable in planning the screening process $[6,8$, 33]. Cascade screening should start with first-degree relatives (i.e. parents, 
siblings, offsprings) and then be extended to second- and third-degree relatives $[6,8,33]$.

\section{$\underline{\text { Risk Notification }}$}

Risk notification underpins cascade screening $[6,8,79]$. Risk notification informs relatives of their risk of $\mathrm{FH}$, the implications for their health, and the availability of clinical and/or genetic testing. Fundamental ethical precepts regarding autonomy, beneficence and justice must be followed.

\section{Contacting and Informing Families}

Cascade screening should begin by contacting first- and then second- degree relatives, who then become probands for risk notification of their own relatives $[6,8,80]$. The index case should discuss family risk notification with the clinician or nurse, who will construct a family pedigree and identify relatives who should be offered testing for $\mathrm{FH}[6,8,33]$. Relatives may be approached either by the index case, the clinical service, or by both $[6,8,79]$. Dual risk notification may be the best option. Genetic counsellors must be involved when sensitive family issues are identified $[6,8,33]$.

Index cases should be provided with written information which clearly explains the diagnostic testing process and implications, and be encouraged to give this to their relatives $[6,8,33]$. Information sent to relatives should be written in general language to avoid alarm and concern, while emphasizing the voluntary nature of testing $[8,79]$, and the health consequences of a diagnosis of $\mathrm{FH}$ being missed if a person decides not to be tested. Communications should also emphasise the health gains of diagnosis and treatment $[6,8,33]$. 
In the absence of a response to the first letter, a second approach by letter or telephone call may be made to the family member [8]. Family members who consent to being assessed for $\mathrm{FH}$ should be offered a standard plasma lipid profile and a genetic test if the family mutation is known and DNA testing available $[6,8,78,80]$. All individuals with potential $\mathrm{FH}$ should be made aware and understand the implications of genetic testing for certain types of insurance cover [8, 81]. Systematic cascade screening for FH is best coordinated centrally by a dedicated service that operates closely with primary care and ideally with a patient organization $[6,8,31]$. Cascade screening should be developed for country-specific and local needs [8]. In less developed countries, family testing in the home environment at weekends may increase the yield of cascade screening, noting also the opportunity for testing extended family members at the invitation of the index case.

\section{$\underline{\text { Risk Notification without Consent }}$}

If the index case does not consent to risk notification of family members it is important to comprehend the rationale behind this, and particularly the family dynamics $[8,45,79,82]$. A decision to risk notify without the consent of the index case should be carefully taken, with attention to the privacy legislation in different countries and localities $[8,83]$. $\mathrm{FH}$ is a potentially lethal condition and if there are high risk features in the family, such as a strong history of premature CVD, contacting of relatives without consent could be justifiable [8, 83]. 


\section{Genetic Testing}

$\mathrm{FH}$ is a dominantly inherited disorder, affected individuals having a $50 \%$ chance of passing the causative mutation to each offspring [1-3]. The majority of cases of $\mathrm{FH}$ are due to mutations in the LDL-receptor $(L D L R)$, apolipoprotein B-100 (APOB) and proprotein convertase subtilisin/kexin type 9 (PCSK9) genes [2]. A pathogenic mutation in one of these genes is identified in about $70 \%$ of phenotypically definite $\mathrm{FH}$ and $20 \%$ of phenotypically probable/possible FH [78, 84-86]. New molecular techniques, such as whole exome sequencing, can lead to the discovery of novel mutations [87]; this may be particularly applicable to under-studied multiethnic populations [88]. Absence of a pathogenic mutation in the presence of a high LDL-cholesterol gene score may indicate polygenic hypercholesterolaemia, and this may be used to limit further search for novel FH causing mutations [89]. About $95 \%$ of the identified mutations are in the $L D L R$ gene, $4-5 \%$ in the $A P O B$ gene and < $1 \%$ in the PCSK9 gene $[2,78]$. Detection of a mutation in a family member allows the definite diagnosis of $\mathrm{FH}$ to be made $[2,5,6,8,78]$. However, failure to detect a mutation does not exclude a diagnosis of $\mathrm{FH}$, particularly if the clinical phenotype is highly suggestive of $\mathrm{FH}[6,8]$. To optimize the use of resources, DNA testing may only be offered to index patients with DLCNS $>5$ or meeting the Simon Broome possible criteria, especially those with a personal history of early onset ( $<60$ years) CVD or imaging evidence of significant subclinical atherosclerosis [8, 57, 84-86].

If a pathogenic mutation is identified in an index case, genetic testing is a cost-effective, accurate and acceptable approach for detecting new cases [77, 
90]. Because of ethical issues involved in genetically testing minors [8, 91], it is best to first genetically test a phenotypically affected parent. Children may initially be genetically tested when parents or first-degree relatives are unknown or deceased $[8,19]$, or with due parental consent, as an acceptable screening practice in certain countries, e.g. The Netherlands $[67,68]$. Genetic testing of families for FH should be co-ordinated by a specialist service with appropriate education and counselling offered to all individuals [5, 6, 8, 33]. Genetic testing in children can be carried out without invasive venepuncture, using a buccal swab or saliva specimen [8].

Genetic testing for $\mathrm{FH}$ has a Tier 1 level of evidence that strongly supports its application in clinical practice [92]. Genetic testing for FH should be carried out in an accredited laboratory that will issue timely results to the requesting medical practitioner [8]. A full sequencing strategy that covers point mutations and insertions/deletions should be performed for the LDLR and PCSK9 genes, and for relevant parts of exons 26 and 29 of the apoB gene [84-86, 93]. Screening for large rearrangements with MPLA analyses should be carried out in people with a high probability of $\mathrm{FH}$ in whom no functional mutations are detected [94]. Accredited laboratories have processes for assessing identified gene mutations or variants and for classifying the variant as clearly pathogenic (a mutation), clearly non-pathogenic (a benign variant) or of uncertain significance (a variant of uncertain significance) [8]; more than 1200 genetic variants in the LDLR have so far been described, but only $79 \%$ are recognised to be pathogenic [95]. The process of screening for genetic mutations, confirming identified genetic variants, assessing pathogenicity and 
issuing a formal report should ideally not take longer than three months [8]. However, genetic mutations may not be detected in $30 \%$ of patients with a definite clinical diagnosis of $\mathrm{FH}[78,84-86]$. In such patients, multiple genetic variants that affect cholesterol metabolism interact to produce a phenocopy of $\mathrm{FH}$ [89], but genetic screening of family members will not be useful. Thus, in a smaller proportion of families, diagnostic testing should be carried out phenotypically using LDL-cholesterol. Specific reference ranges for patients with high likelihood, low likelihood and diagnosis uncertain will have to be derived from populations with and without $\mathrm{FH}$ in each country [70]. Clinical management of patients should evidently be based on the plasma lipid phenotype and overall CVD risk status, and not on the genetic test result $[6,8$, $9,60]$.

\section{Management of Adults}

$\mathrm{FH}$ is associated with a moderately severe to very severe increase in the lifelong exposure to the atherogenic effects of LDL-cholesterol [53, 66]. It warrants aggressive, life-long management from a young age [19-21, 96].

\section{$\underline{\text { LDL-Cholesterol and related lipid targets }}$}

Because of lack of clinical trial evidence [96, 97], clear therapeutic targets for plasma LDL-cholesterol cannot be categorically defined for $\mathrm{FH}[6-11,13]$. The following is synthesized from various international guidelines [6-13, 22, 59]. In heterozygous $\mathrm{FH}[6,9]$, therapy should initially aim for at least a $50 \%$ reduction in plasma LDL-cholesterol, followed by an LDL-cholesterol of $<2.5$ $\mathrm{mmol} / \mathrm{L}$ (absence of $\mathrm{CHD}$ or other major risk factors) and $<1.8 \mathrm{mmol} / \mathrm{L}$ 
(presence of CHD or other major risk factors) [10-12]; three targets for LDLcholesterol according to CV risk stratification have also been described and are reasonable [8], but not universally ratified [97]. Untreated LDL-cholesterol burden, or life years exposure, should be considered a major risk factor for driving more intensive and/or earlier therapy [53]. However, all recommended targets are difficult to achieve in the majority of $\mathrm{FH}$ patients with currently available treatments $[5,8,18]$, so that the maximal LDL-cholesterol reduction that can be tolerated with therapy is a pragmatic strategy, particularly for higher risk patients with $\mathrm{FH}$. The LDL-cholesterol of homozygotes should accordingly be reduced as much as possible $[8,32,64]$, noting subsequent recommendations on use of apheresis. Therapeutic targets for apoB and nonHDL-cholesterol have not been defined in $\mathrm{FH}$ [8], but with co-existent metabolic syndrome or diabetes targets recommended by other expert bodies should be adopted [12-14, 59, 98]. A therapeutic target for $L p(a)$ has been specified elsewhere, but the evidence for its use in $\mathrm{FH}$ is limited [49]. Other than when investigating symptomatic patients or managing homozygotes [8], we do not consider that there is a role for cardiovascular imaging in monitoring and guiding therapy.

\section{Modification of lifestyle and non-cholesterol risk factors}

All patients with $\mathrm{FH}$ should be counselled on lifestyle modifications [6-14, 99]. Dietary modification to lower the intake of saturated fat, trans-unsaturated fat, and cholesterol contributes to improvements in the plasma lipid profile [100102]. A heart-healthy diet should be promoted and regular intake of fruits and vegetables, whole grains, tree nuts, low-fat and non-fat dairy products, beans, 
fish and lean meats encouraged. Alcohol intake should be moderated and psychological stress addressed $[8,46]$. Expert counselling may be indicated [102]. A Mediterranean-type diet supplemented with extra virgin olive oil or nuts may have particular benefits in FH [103], but its acceptance will be culturally dependent. Dietary supplementation with plant sterols or stanols may be employed to incrementally lower plasma LDL-cholesterol [104]. Avoidance and cessation of smoking is mandatory. Smoking cessation can be facilitated with either nicotine replacement products or drugs that modulate the intensity of nicotine withdrawal [11]. Passive smoking should also be discouraged in families. Hypertension should be treated to guideline levels [105]. Patients who are obese and/or insulin resistant should be counselled on weight loss and aerobic exercise regimens [8, 100-102]. Prior to initiation of an exercise regimen, some patients will warrant stress testing (electro- or echocardiography, nuclear perfusion scanning) to assess myocardial functional capacity and the possibility of silent ischaemia $[11,45,106]$. Diabetes should be treated according to recommended guidelines [107]. Low dose aspirin should be used in high risk $\mathrm{FH}$ and considered in lower risk patients $[8,11,96]$.

\section{Pharmacologic Therapy}

The mainstay of managing $\mathrm{FH}$ is therapy with a high potency statin, generally administered at the highest dose tolerated within 6 months of first consultation $[6-9,13]$. Statins reduce the risk for cardiovascular events [108-113] and progression of atherosclerosis in $\mathrm{FH}$ [56], and their use is cost-effective [77, 114, 115]. Adjuvant therapy with ezetimibe, bile acid sequestrants, plant 
stanols/sterols, and niacin (or its derivatives) may often also be required [21, 116-120]. Patients may require 3 or more drugs to achieve adequate LDLcholesterol reduction, which is particularly important in secondary prevention $[8,18,120]$. With hypertriglyceridaemia, use of fenofibrate or omega-3 fish oils may be advisable $[13,98]$, and niacin could be considered when plasma LDLcholesterol and/or $\operatorname{Lp}(\mathrm{a})$ are also not at target $[49,119]$. Probucol is used in Japan, Korea and China. Probucol is a potent antioxidant and, despite lowering HDL-cholesterol, can regress xanthomata and reduce CVD events in $\mathrm{FH}[121]$.

The effectiveness of statins, ezetimibe and bile acid sequestrants relates to upregulation of hepatic LDLRs [41]. Given that patients with homozygous FH have a severe or total deficiency in LDLR function, their response to LDL lowering therapies is usually markedly attenuated [32]. Statins and ezetimibe can lower LDL-cholesterol in homozygous $\mathrm{FH}$ by potentially decreasing hepatic secretion of apoB $[32,122]$, but these patients usually require apheresis [32, 64]. Homozygous patients with LDLR null mutations (function $<2 \%$ of normal) are less responsive to pharmacotherapy and have a worse prognosis than those with LDLR defective mutations (function 2-25\% of normal) [32]. If apheresis is not available, consideration should be given to the addition of lomitapide [123] or mipomersen [124] to further lower LDLcholesterol, noting country-specific licensing and use of special access schemes. Although apparently safe in studies that have facilitated their approval for prescription use, experience with these new agents in clinical 
practice is very early and careful attention to guidance from the manufacturers and the regulatory agencies is essential.

It is critical to ensure that all $\mathrm{FH}$ patients adhere to the recommended treatment regimens $[8,125,126]$. Patients should be counselled on all aspects of their care, including the warning signs of drug related toxicity [125, 126].

\section{Potential Medication Toxicity}

All systemically absorbed cholesterol-lowering therapies can potentially be hepatotoxic and myotoxic [118, 119], although in practice the chances of severe toxicity are extremely low. Given that the majority of patients with FH will be treated with two or more medications [8, 13, 18, 117], the risk for adverse events is higher than with monotherapy. Plasma hepatic aminotransferases should be measured prior to initiating a statin [127]. If baseline levels are abnormal, hepatic ultrasonography should be considered. A significant percentage of patients requiring drugs in developed and developing countries have insulin resistance and hepatic steatosis. Plasma glucose should particularly be monitored in all patients with impaired fasting glucose [128], as well as in those with risk factors for type 2 diabetes, including metabolic syndrome. Plasma aminotransferases should be monitored with statins $[8,127]$, noting the recent FDA recommendation that this need only be undertaken as clinically necessary and not routinely (http://fda.org/Drugs/DrugSafety/ucm293101.htm). Lipid lowering drugs should be discontinued if plasma aminotransferases increase to 3 times the upper limit of normal on two occasions within a period of one month. The specific 
regimen can be re-evaluated and patients rechallenged with a different statin and then drugs re-introduced piecemeal with careful monitoring of plasma aminotransferases. Both mipomersen and lomitapide have FDA black box warnings concerning the potential risk of hepatotoxicity.

Statin related myalgia is a significant problem in the community setting; it is dose-dependent and varies among statins $[129,130]$. Patients should be counselled about warning signs of myopathy and rhabdomyolysis. Older age, frailty, reduced overall skeletal muscle mass, chronic kidney disease, hypothyroidism, alcoholism, underlying muscle disorders, and drug interactions all increase the risk of myopathy [130, 131]. Plasma creatine kinase (CK) levels and a careful physical examination should be performed prior to starting therapy, since there are many causes of myopathy and arthropathy other than statins $[130,131]$. Similarly, patients reporting musculoskeletal symptoms on statins require careful clinical evaluation, including repeat plasma CK and exceptionally electromyography and referral to a specialist $[130,131]$. The combination of gemfibrozil with a statin should be particularly avoided [129-131], the risk of myopathy being significantly lower with fenofibrate $[132,133]$. Statin myopathy should be managed according to expert recommendations [59, 130, 131, 134]. Ezetimibe is well tolerated and has a statin dose-sparing effect $[116,117]$. Bile acid sequestrants cause constipation and abdominal discomfort and can impair the absorption of anionic drugs and vitamins; tolerability is greatest with colesevelam [118, 135]. In addition to induction of flushing, patients treated with niacin should also be monitored for possible elevations in serum uric acid 
and glucose and reductions in platelets [136]. Niacin combined with laropiprant, an anti-flushing agent, is no longer commercially available, owing to unfavourable outcomes in a recent trial [137]. Patients should report any new medications prescribed by other health care providers to minimize risk for drug interactions $[118,133]$. Patients with reduced glomerular filtration rates may require dose adjustment of lipid modifying medications (e.g. specific statins or fibrates) [118]. Neither atorvastatin, pravastatin nor pitavastatin require dose adjustments with chronic kidney disease since they are not substantially renally excreted $[118,127]$.

Women: contraception, pregnancy and menopausal hormone therapy. Low estrogen-containing oral agents, intra-uterine devices and barrier techniques are the preferred methods of contraception for women with $\mathrm{FH}$ [8, $22,138,139]$. The latter two are preferable for those older than 35 years [8]. All women and girls of childbearing age should receive advice on contraception and pre-pregnancy counselling before starting a statin and this should be reviewed annually $[8,138,140]$. Statins and other systemically absorbed lipid regulating drugs should be discontinued 3 months prior to conception and during pregnancy and lactation [8, 138]. However, women who become pregnant accidentally while on a statin could be re-assured that the likelihood of foetal complications is low $[8,140]$.

Controlling hypercholesterolaemia during pregnancy is particularly important in women with established $\operatorname{CHD}[8,9,22]$; it may also decrease the severity of $\mathrm{FH}$ in offspring who inherit the condition [141]. Bile acid sequestrants are the 
only safe agents to control hypercholesterolaemia in pregnancy $[8,9,118$, 142], but only modestly lower plasma LDL-cholesterol levels and gastrointestinal side-effects remain a problem [118, 135]; colesevelam is more tolerable than older resins. During breastfeeding, resins could be employed to lower LDL-cholesterol where indicated [8, 22]. More data are required on the outcomes of pregnancy in women with $\mathrm{FH}$ and on the effect of statins on the foetus in the first trimester [140]; an appropriate registry of patients is recommended [8]. Pregnant women with heterozygous FH and established $\mathrm{CHD}$, or with homozygous $\mathrm{FH}$, should be considered for apheresis $[8,9,22$, 64, 142].

When one or both members of a couple have $\mathrm{FH}$, several options may enable the couple to avoid having a child affected by $\mathrm{FH}$. These include not conceiving, adoption, using donor gametes, prenatal diagnosis using chorionic villus sampling or amniocentesis, and pre-implantation genetic diagnosis [8]. Referral for expert counselling is accordingly recommended [8].

The effect of menopausal hormone therapy (MHT) on risk of CHD in postmenopausal women with $\mathrm{FH}$ is unclear. On the basis of data from other populations, MHT should be avoided in women with $\mathrm{FH}$, except for relief of menopausal symptoms that cannot be controlled with safe natural remedies $[22,143,144]$, in which case a regimen based on cyclical transdermal oestrogen should be employed. 
It is generally agreed that targets for LDL-cholesterol treatment in children need not be as low as adults $[8,9,19,20,22,65]$. As in adults, good evidence for an absolute or relative target does not exist in children; international guidelines are consequently not uniform in their recommendations $[8,9,19$, $20,22,65]$. Early cholesterol-lowering treatment can substantially alter the natural history of $\mathrm{FH}[53,56,108-112,145]$. Although systematic reviews confirm the safety of currently employed statins in children $[146,147]$, the long-term sequelae of high intensity statin regimens are unknown. Good longterm data on the safety of statins started early in life are therefore required $[148,149]$, emphasizing the need to establish a suitable international registry [150]. The plasma LDL-cholesterol targets for children aged 8 to 10 years should be $<4.0 \mathrm{mmol} / \mathrm{L}$ and for those older than 10 years $<3.5 \mathrm{mmol} / \mathrm{L}[8,19$, $20,22,65,66,73,145,148]$. Boys and girls should be treated to similar targets, but treatment targets could be lowered and therapy intensified in those with a particularly adverse family history of CHD or in the presence of other major cardiovascular risk factors $[8,19,43,44,63,65,73]$. Therapeutic targets for non-HDL-cholesterol, apoB and $\mathrm{Lp}(\mathrm{a})$ have not been clearly defined for children with $\mathrm{FH}$.

Treatment begins with a heart-healthy diet management that is best administered by a paediatric dietician $[73,101]$. The diet should typically contain $<30 \%$ of calories from total fat, $<7 \%$ of calories from saturated fat, and ideally $<200 \mathrm{mg}$ of cholesterol/day [20,73, 101]. The diet should include nutrient dense foods with appropriate energy to maintain optimal body weight. 
Fruits and vegetables, whole grains, low-fat dairy products, beans, fish and lean meats should be encouraged. Encouraging a Mediterranean diet may be beneficial and particularly acceptable in certain cultures [103]. Dietary supplementation with plant sterols or stanols (sitosterol or sitostanol) may be considered to lower LDL-cholesterol levels [151]. Physical activity should be promoted and active and passive smoking strongly discouraged $[8,20,65,66$, 73, 101]. Primordial prevention of the development of risk factors is advised $[8,20,65,66]$. Additional existing cardiovascular risk factors should be treated according to recommended guidelines $[73,101]$. $\mathrm{FH}$ is not only a disorder that should be diagnosed in a family context, but also managed in a similar manner; the entire nuclear family should be strongly encouraged to adopt and support adherence to a lifestyle that addresses all major cardiovascular risk factors.

Drug treatment will be required in a great majority of patients with heterozygous $\mathrm{FH}$ and should be initiated in those with plasma LDL-cholesterol levels (measured on two occasions) above targets after diet management [8, $19,20,22,65,73]$. Agents tested in clinical trials and approved for use by regulatory agencies should be used $[8,19,20,22,65,66,73]$; statin drugs are preferred and should be initiated at low doses [146, 147]. Statin treatment with approved medications can be initiated at 8-10 years of age and not delayed until 18 years $[8,19,20,22,65,66,73]$. Children with a particularly adverse family history of CHD and other major risk factors could be considered for earlier treatment with statins $[8,19,43,44,65,73,145]$; this may be especially important in boys [1, 3, 43, 44]. If goals are not achieved, 
consideration should be given to the addition of ezetimibe or bile acid sequestrants $[8,19,65,66,148,149]$. Balancing the need to achieve LDLcholesterol targets with possible side effects should be considered in individualizing drug therapy $[148,149]$. Children with homozygous FH should be referred to a specialist centre: medications should be initiated at diagnosis, higher potency statins in combination with other agents will be required, and apheresis must be considered [8, 19, 20, 22, 61, 65, 73, 152].

Prior to initiating statin therapy, plasma aminotransferases, CK, glucose, and creatinine should be measured $[8,19,20,22,65,148,149]$. After starting therapy, weight, growth, physical and sexual development should be monitored. Plasma aminotransferases should be monitored routinely, as should glucose and glycated haemoglobin if there are co-existent risk factors for diabetes. Plasma CK should be assessed if musculoskeletal symptoms are reported. Statin myopathy should be managed according to adult guidelines [129-131]. Adolescent girls should be counselled to stop statins when contemplating or at risk of pregnancy $[8,138,140]$.

Paediatric patients with uncomplicated and well-controlled $\mathrm{FH}$ could be managed in general practice $[8,20,65]$. Patients with severely elevated LDLcholesterol, multiple cardiovascular risk factors, complications of pharmacologic therapy, or homozygous $\mathrm{FH}$ should be managed by a specialist $[8,20,22,65,73]$. Family and transitional care clinics are recommended $[8,65]$. Carotid ultrasonography has been employed in research studies [52, 147], but its use and that of other cardiovascular imaging modalities cannot at present be recommended for monitoring therapy 
in individual paediatric patients with heterozygous FH. Establishing clinical registries is essential for improving the overall care of paediatric patients with $\mathrm{FH}[150]$.

\section{Lipoprotein apheresis and other invasive therapies}

Lipoprotein apheresis (LA) is an extracorporeal treatment that removes apoBcontaining lipoproteins from the circulation $[64,152,153]$. The removal of LDL by LA improves CHD outcomes, progression of atherosclerosis and aortic fibrosis, endothelial function and coagulation in $\mathrm{FH}[142,153,154]$. LA is FDA approved therapy that is indicated for patients with homozygous (or compound heterozygous) $\mathrm{FH}$ or severe heterozygous $\mathrm{FH}$ with progressive CHD, who are refractory or intolerant to maximal pharmacotherapy $[8,22$, 142, 153-155]. By contrast to homozygous $\mathrm{FH}$, the social/patient acceptability and cost-effectiveness of LA for treating refractory heterozygous $\mathrm{FH}$ remains unclear and needs further evaluation [156]. Elevation in plasma Lp(a) levels is a reimbursable indication for LA in Germany, but the evidence supporting the value of apheresis beyond reduction in LDL-cholesterol is questionable [152, 154, 157]. In homozygous children, LA should be considered by age 5 years and no later than 8 years $[8,22,152,158]$. Untreated patients with a homozygous phenotype typically have plasma LDL-cholesterol $>13 \mathrm{mmol} / \mathrm{L}$ and should be treated with maximally tolerated pharmacotherapy for at least 6 months before considering LA [8, 22, 64, 152-155]. Untreated heterozygotes typically have plasma LDL- cholesterol from 5 to $13 \mathrm{mmol} / \mathrm{L}$ and may be truly non-responders to or be intolerant of pharmacotherapy [8, 22, 32, 64]. LDLcholesterol criteria for selecting the above patients for apheresis have been 
recommended elsewhere $[8,64,152,153,155]$, but should be modified according to clinical context; simple criteria are a reduction in LDL-cholesterol of less than $50 \%$ or LDL-cholesterol $>5 \mathrm{mmol} / \mathrm{L}$ on diet and maximally tolerated pharmacotherapy, which should be continued during LA $[8,64]$. Different thresholds for LDL-cholesterol may be set according to the availability of resources for apheresis. Patients must be psychologically and clinically stable and committed to treatment [8]. Imaging should be carried out at baseline to assess aortic stenosis and aneurysms $[8,22,64,152,155]$. Contraindications to apheresis methods employing heparin include haemorrhagic diatheses, resistance to adequate coagulation and hypersensitivity to heparin. LA is efficacious, tolerable and safe for children with severe $\mathrm{FH}$ and may be commenced after the age of 5 years $[8,152,158$, 159], or earlier in exceptional circumstances. While lower body weight is a recognised risk factor for complications, successful outcomes have been reported with LA in very young children with homozygous $\mathrm{FH}[152,159,160]$. Women with severe FH may be successfully treated during pregnancy $[8,22$, 155].

There are several LA methods that are selective for LDL and all acutely lower plasma LDL-cholesterol and $L p(a)$ levels by 50 to $70 \%$ following a single treatment $[153,155]$. The FDA approved methods involve the extracorporeal precipitation of apoB-containing lipoprotein with dextran sulphate or heparin [142], while in other countries, alternative systems (immunoadsorption, double cascade filtration or haemoperfusion with direct absorption of lipoproteins units, dextran sulphate or polyacrylate) are available $[64,152,153,155]$. 
Plasma exchange may be used, but is not selective for LDL. The choice of method will depend on local expertise and resources [153, 155]. A major barrier is the cost of treatment, which is comparable to haemodialysis [8]. Therapeutic outcomes and costs can be optimized by collaborating with a specialty experienced in apheresis, such as transfusion medicine $[8,155]$. The cost-effectiveness of treating homozygous FH with LA appears to be greater than for heterozygous $\mathrm{FH}$, questioning whether present healthcare systems could meet a rising demand for LA posed by refractory heterozygous $\mathrm{FH}$ patients [156]. In developing countries, creative approaches, such as corporate support and public donations, should be adopted to support the funding of LA. There is a need for an extended international network of treatment centres and registry of patients on LA $[150,152,157]$.

The frequency of LA should be adjusted to achieve a time-average plasma LDL-cholesterol concentration between therapy of $<6.5 \mathrm{mmol} / \mathrm{L}$ and $<2.5$ $\mathrm{mmol} / \mathrm{L}$ for homozygotes and heterozygotes $[8,64,155]$, respectively; a mean reduction of $65 \%$ in LDL-cholesterol relative to no treatment is a simple target. This will usually require an acute reduction of $\geq 70 \%$ in LDL-cholesterol and weekly or fortnightly treatments; weekly treatments may be required in very severe homozygous FH [152-155]. Statins should be continued to slow postexchange rebound in LDL-cholesterol $[8,64,155]$. Angiotensin converting enzyme inhibitors are contra-indicated with most systems, particularly the dextran sulphate LDL absorption and haemoperfusion methods, because of bradykinin reactions [8, 64, 152, 153]; side effects (nausea, hypotension, vasovagal episodes, hypocalcaemia, anaemia, sepsis) are not uncommon, 
but are rarely serious. Patients who are intolerant of a particular method of LA should be tested on an alternative method, including plasma exchange if required $[8,64,153]$. Because of the demands of treatment, psychological status and quality of life should be addressed [8], recent data suggesting that lower quality of life may relate specifically to the severity of CVD [161]. Longterm efficacy of treatment on carotid and aortic valve/root atherosclerosis should be assessed every 2 years in homozygotes using standard imaging methods [8, 155, 162]. Regular monitoring with exercise electro- or echocardiography and review by a cardiologist are recommended.

Lomitapide should be considered as an adjunctive treatment to further lower LDL-cholesterol in adults with homozygous FH on LA [123, 152, 154], as well as in children and adolescents with homozygous $\mathrm{FH}$ (under special access or compassionate use schemes) on LA with rapidly progressive atherosclerosis. By contrast to lomitapide, experience with use of mipomersen has not yet been reported in homozygous $\mathrm{FH}$ patients on LA. In those who cannot tolerate lomitapide, mipomersen should be accordingly considered [124, 152, 154]. Novel LDL-cholesterol lowering therapies may reduce the need for or the frequency of LA in severe $\mathrm{FH}[152,154,163-165]$, but this needs to be demonstrated.

Orthotopic liver transplantation should also be considered in younger homozygous patients when LA is not available, or cannot be tolerated, and LDL-cholesterol cannot be adequately controlled with intensive pharmacotherapy [8, 166]; pre-emptive transplantation has been proposed but experience is limited [167]. Coronary artery bypass surgery, aortic valve 
replacement or a combined heart transplant should be considered according to clinical context prior to liver transplantation [168, 169]. Partial ileal bypass should be considered in heterozygous patients who are drug-intolerant [170]. Portacaval shunting can theoretically decrease the hepatic secretion of LDL in homozygous $\mathrm{FH}$, but $\mathrm{LDL}$-cholesterol reduction is variable and the procedure carries a high risk of encephalopathy; it could exceptionally be considered to treat severe homozygotes in countries where the above treatments are not available [171]. There may be a future role for gene therapy in treating severe $\mathrm{FH}[172,173]$.

\section{Emerging Therapies}

Many patients with $\mathrm{FH}$ cannot attain optimal and sustained reductions in plasma levels of LDL-cholesterol [18, 32]. This has prompted the development of highly innovative therapies that can provide substantive reductions in LDLcholesterol additional to standard therapies [164, 165], with significant implications also for the treatment of homozygous FH [174]. The long-term efficacy, safety and tolerability of these agents remain to be demonstrated, however. Clinical registries of patients treated with all new therapies is recommended [150].

\section{PCSK9 Inhibition}

Proprotein convertase subtilisin-like kexin type 9 (PCSK9) is a serine protease secreted by hepatocytes that regulates the expression of the LDLR [175]. PCSK9 complexes with the LDLR and is taken up together with the adaptor protein $\mathrm{ARH}$ (autosomal recessive hypercholesterolemia) in clathrin coated 
pits by hepatocytes [175]. PCSK9 either prevents the recycling of LDLR to the hepatocyte cell surface from the endosomal compartment or chaperones the LDLR to the lysosome for degradation [175]. Loss-of-function genetic variants in PCSK9 enhance hepatic LDL receptor activity, with significant lifelong reductions in plasma LDL-cholesterol and reduced risk of CHD [175]; conversely, dominant gain-of-function mutations lead to a phenotype similar to $\mathrm{FH}[2,175]$.

Therapeutic human monoclonal antibodies (Mabs) against PCSK9 increase both the residence time of LDLR on the cell surface and receptor density, leading to augmented clearance of LDL-cholesterol from the circulation [175]. REGN727/SAR236553 demonstrates a dose-response capacity to reduce serum levels of LDL-cholesterol (40-72\%) in patients with heterozygous $\mathrm{FH}$ receiving statin therapy with or without ezetimibe [176] and in patients with primary hypercholesterolaemia with or without statin therapy $[177,178]$. Similarly, AMG 145 demonstrates a dose-response capacity to reduce plasma LDL-cholesterol $41-66 \%$ and has been tested in patients with heterozygous $\mathrm{FH}$ [179], as well as in primary hypercholesterolaemia with or without statin therapy [180, 181]. AMG 145 can also lower plasma LDL-cholesterol in receptor defective homozygous FH patients [182]. Importantly, PCSK9 Mabs also significantly reduce plasma apoB, total cholesterol, non-HDL-cholesterol, and $L p(a)$ [175-181]. These Mabs are in phase 3 trials and are not yet approved for use, but clearly hold great promise either as monotherapy or adjuvant therapy in the management of $\mathrm{FH}[164,165,175]$. The long-term efficacy and safety of these agents needs to be established In $\mathrm{FH}$. 


\section{Mipomersen}

Mipomersen $\left(\mathrm{Kynamro}^{\mathrm{TM}}\right.$ ) is an antisense 20-mer oligonucleotide that binds to a complementary sequence messenger RNA encoding apoB, thereby inhibiting ribosomal translation [183]. By inhibiting the biosynthesis of apoB, hepatic VLDL production and secretion are significantly reduced. Mipomersen consists of a phosphorotioate backbone and 2'-O-(2-methoxyethyl)-modified ends which provide biological stability [183]. Subsequent to subcutaneous injection, Mipomersen is concentrated in the liver where it undergoes catabolism via the action of hepatic endonucleases and exonucleases [183]. Mipomersen is FDA approved for use in patients with homozygous $\mathrm{FH}$. Mipomersen has been shown to reduce serum LDL-cholesterol by approximately $25 \%, 28 \%$, and $36 \%$ in patients with homozygous $\mathrm{FH}$ [124], heterozygous $\mathrm{FH}$ [184], and severe hypercholesterolemia with or without CHD [185], respectively. Mipomersen also induces substantial reductions in total cholesterol, apoB, triglycerides, non-HDL-cholesterol, and Lp(a) [124, 183185]. In addition to frequent injection site reactions and short-lived fatigue and myalgia, mipomersen can induce hepatic steatosis (assessed by magnetic resonance imaging) in $16 \%$ of patients, as well as elevations in plasma aminotransferases in $8 \%$ of patients $[124,183-185]$. These hepatic changes apparently resolve on discontinuing the drug [183]. Mipomersen has orphan drug status and, because of the risk of hepatotoxicity, in the US can only be prescribed through a Risk Evaluation Mitigation Strategy (REMS) program (http://www.fda.gov/Drugs/DrugSafety/PostmarketDrugSafetylnformationforPa tientsandProviders/ucm111350.htm). 


\section{Lomitapide}

Microsomal triglyceride transfer protein (MTP) localizes to the endoplasmic reticulum of hepatocytes and enterocytes and transfers triglycerides into VLDL in the liver and chylomicrons in the intestine [186]. Lomitapide (Juxtapid ${ }^{\mathrm{TM}}$ ) is an oral MTP inhibitor that decreases the hepatic production and secretion of VLDL. Lomitapide is licensed for the treatment of homozygous $\mathrm{FH}$ in the US and Europe as an add-on therapy [186]. In a multi-centre study of such patients lomitapide reduced LDL-cholesterol by $50 \%, 44 \%$, and $38 \%$ at 26,56 , and 78 weeks respectively [123]. Lomitapide therapy may also result in significant reductions in other lipids and lipoproteins, including total cholesterol, apoB, triglyceride, non-HDL-cholesterol, and $\operatorname{Lp}(\mathrm{a})[123,186]$. Lomitapide may be hepatotoxic, can elevate plasma aminotransferases, and can increase intrahepatic fat content by approximately $6 \%$ after 26 and 78 weeks of therapy [123, 186]. Cytochrome P450 3A4 inhibitors increase exposure to lomitapide [186]. It can induce gastrointestinal symptoms related to reduced small intestine absorption of fat, so that dietary fat restriction is frequently required to control such symptoms. Lomitapide may reduce the absorption of fat-soluble vitamins and essential fatty acids, so coadministration of appropriate supplements is recommended. Because of the risk of hepatotoxicity, in the US lomitapide must also be prescribed through an FDA approved REMS program.

Mipomersen and lomitapide are both FDA approved for homozygous $\mathrm{FH}$. PCSK9 inhibitors are not yet licensed for use in $\mathrm{FH}$, but clinical trial data suggest that they may have broad applications for patients with heterozygous 
$\mathrm{FH}$, who are not at LDL-cholesterol targets on maximal statin therapy [164, $165,176,179]$ or who are intolerant to statins [187]. All three classes of agents may reduce the need for $L A$ and other radical therapies for severe $\mathrm{FH}$. The results of trials of cholesteryl ester transfer protein inhibitors have been universally disappointing to date [164, 165], but the efficacy of anacetrapib is currently being tested in a large study of patients with heterozygous $\mathrm{FH}$ [164].

\section{Organization and Development of Care}

In spite of the recent explosion of interest and research in $\mathrm{FH}$, the care of patients and families remains suboptimal [18, 21, 25, 188-190]. This provides an important mandate to standardise and improve service delivery at all levels. The development and implementation of initiatives and strategies to improve the care of $\mathrm{FH}$ requires a close collaboration between healthcare systems, patient support groups and related non-government organizations and health networks $[8,31,33,97,191,192]$. Care pathways for patient flow among all health providers, including primary care, should be developed and be specified for local needs [8, 31, 33, 97]. Establishing a national network of clinics managing people with $\mathrm{FH}$ is recommended for standardising care and facilitating research $[8,80,189,190]$. FH urgently needs an International Classification of Diseases (ICD)-10 and/or a Diagnosis-Related Groups (DRG) code to standardise assessment of quality outcomes and organisational performance, as well as to facilitate research, healthcare financing and reimbursement strategies. 
Models of care for $\mathrm{FH}$ should be multidisciplinary $[8,31,33]$ and, in principle, centrally co-ordinated $[5,8,31,33,80,193]$. Services should be managed by personnel accredited in cardiovascular prevention [8, 31, 194], and should address all aspects of care, including health-related quality of life [46, 195]. Well controlled and low complexity patients could be transitioned to primary care for long-term management, while high complexity patients should be followed-up by a service with special expertise in lipid management [8, 31, 33]. Review intervals will vary according to clinical context. Patients with severe $\mathrm{FH}$ on apheresis require careful lifetime follow-up by specialist services $[8,64,152,155]$. Primary care providers have an important role in detecting index cases $[8,27]$, but cascade screening should be co-ordinated centrally within a framework that integrates specialist and primary care $[8,27$, $31,193]$. Education and training of primary care providers in lipid management is important for improving and maintaining the total quality of care $[8,33,196]$. A structured review should be offered at least annually to all patients $[8,33]$. This is particularly important for low complexity patients who may be more at risk of loss to follow-up; the process could be centrally monitored via a registry [150]. A telehealth programme should be employed for remote care $[8,197]$. Children are best reviewed in a specialist paediatric clinic, with appropriate arrangement made for transitional care [8, 18, 20, 65]; an adult-paediatric clinic may be useful for families [65].

Nurses have a role in co-ordinating screening, as well as in clinical care, medication support, education and training, audit and research, multidisciplinary liaison [8, 80, 198-200] and working with a family support 
group [8, 31, 33]. Dietetic services are highly desirable [8, 99-101]. Advice from health and adolescent psychologists $[46,82,201]$ and exercise physiologists [102] may be required. Pharmacists may have a special role in case detection, medication support and research $[8,202]$. A multidisciplinary approach should be adopted to address the quality of life of $\mathrm{FH}$ patients on various treatment modalities.

Links with clinical genetics are important for special counselling during cascade screening $[8,201]$. Not all families or patients with $\mathrm{FH}$ require genetic counselling, but some exposure and basic training in the principles of genetic counselling is important for managing $\mathrm{FH}[8,78,201]$.

FH services should also have close links with laboratory medicine and access to routine and advanced lipid analyses $[8,30,31]$. DNA testing should only be carried out by accredited laboratories that can screen for mutations in all the major genes of interest $[8,78,86]$. Adequate patient assessment requires access to cardiac and imaging facilities, including treadmill testing, myocardial perfusion scanning and ultrasonography; close links with cardiology are essential $[7,8,54,203]$. Collaboration with a transfusion medicine or dialysis unit is important for managing apheresis $[8,152,153,155]$.

A specialised database for storing clinical and family data and information technology support systems is essential for effective provision of services [8, 30, 31]. Computerised programs should be capable of pedigree drawing, workflow management, production of template letters, archiving data, clinical audits and research. An international database with information on mutations 
recognised as causing $\mathrm{FH}[95]$ is available, but should be developed for those countries or healthcare systems adopting DNA testing [84-86].

A well-designed and comprehensive clinical registry provides invaluable information for research and audit, as well for improving the quality of care $[26,150]$. A registry can facilitate the co-ordination of cascade screening at a local, community and national level, increasing also the cost-efficiency of DNA testing where a mutation has been previously identified and registered in a family [150]. Hybrid enrolment options, including patient enrolment, may enhance the identification of $\mathrm{FH}$. Every effort should be made to establish an active association for patients and families via a support group [8, 30, 31]. This forum can provide a useful network for facilitating mutual support and education, establishing an effective advocacy group and interacting with health policy makers, and developing a national registry of affected families. All models of care must address the perspectives and requirements of patients and families [46, 195].

\section{Conclusion: into the future}

This international guidance is derived from knowledge of best contemporary practice, and aims to achieve the best outcomes for patients with $\mathrm{FH}$ by providing a standard of practice that will hopefully remove variability and inequalities in the care of $\mathrm{FH}$ worldwide. The recommendations cannot, however, meet universal needs for the care of $\mathrm{FH}$. They therefore need to be complemented by judicious clinical judgment and adjusted for country-specific and local healthcare needs and resources. Clinical trials in people with $\mathrm{FH}$ are 
needed to close evidence gaps. Research agendas should be broad, but also specific to national and local needs. Research should ideally be conducted by clinical networks and integrated into a quality cycle to improve the development of models of care [204]. FH requires an ICD-10 classification code as a matter of priority. Future developments in the healthcare of $\mathrm{FH}$ need to evolve within the framework of the Chronic Care Model [23], and hence in a positive policy environment. This will entail establishing effective partnerships with a wide spectrum of stakeholders, including patient support groups, public participants, heart foundations and related non-government organizations, universities and academic centres, as well as with health economists, policy makers and government ministers [8, 191, 192]. 
International Familial Hypercholesterolaemia Foundation Consensus Group Writing and Steering Committee:

Gerald F. Watts (Australia; Chair), Samuel Gidding (US), Anthony Wierzbicki (UK), Peter P. Toth (US).

Contributors:

Rodrigo Alonso (Spain), W. Virgil Brown (US), Eric Bruckert (France), Joep Defesche (Netherlands), Khoo Kah Lin (Malaysia), Michael Livingston (UK), Pedro Mata (Spain), Klaus G. Parhofer (Germany)' Frederick J. Raal (South Africa), Raul D. Santos (Brazil), Eric J. G. Sijbrands (Netherlands), William G. Simpson (Scotland), David R. Sullivan (Australia), Andrey V. Susekov (Russia), Brian Tomlinson (Hong Kong, China), Albert Wiegman (Netherlands), Shizuya Yamashita (Japan), John J. P. Kastelein (Netherlands).

International FH Foundation Board Members:

RA (Advisor), JD (Chairman), JJPK (Hon. President)), ML (Executive Director), PM (Trustee), RDS (Advisor), GFW (Trustee). The International FH Foundation, a UK based Not For Profit Charity, was commissioned with the major aim of improving the care of $\mathrm{FH}$ worldwide. An international board of patients, clinicians and other skilled representatives has set new targets to address strategic priorities, which through continually improving communications between clinicians with interests in $\mathrm{FH}$, aims to establish and support new country foundations, campaigning, consensus, research, education, patient registries and family practitioner engagement projects.

\section{Process:}

GFW and DS arranged a series of workshops and discussions at the International Atherosclerosis Society (Sydney 2012) that involved 16 members of the group and addressed evidence for treatment, screening and DNA testing, paediatric management, novel therapies, health economics, regional diversity in management, and models of care. Workshop moderators 
(GFW, DS, SG, AW, PPT) identified and collated consensus-based on published research, clinical experience, common themes, expert opinion and other international guidelines on $\mathrm{FH}$. To gauge wider international opinion a brief questionnaire on potentially contentious issues in $\mathrm{FH}$ (screening options, DNA testing, risk stratification, testing and treatment of children, use of imaging, and therapeutic targets) was completed by all members of the group and a group of 26 international experts. The majority view was employed to inform further consensus, as discussed and agreed by group members (AW, JD, ML, PPT, BT, RDS, WGS, GFW) at a satellite workshops arranged by the International FH Foundation at the $80^{\text {th }}$ Congress of the European Atherosclerosis Society (Milan, 2012) and the World Congress of Clinical Lipidology (Budapest, 2012). GFW produced a first copy of the recommendations and manuscript, which was subsequently extended and revised by SG, AW and PPT, with additional comments received from all members of group. At three teleconferences GFW, SG, AW and PPT discussed and fully concurred on the levels of evidence and gradings for the recommendations, based on previous consensus, published literature and expert opinion. The recommendations were again discussed and agreed with selected group members (AW, PM, FJR, BT, RA, ML) at a workshop at the $81^{\text {st }}$ Congress of the European Atherosclerosis Society (Lyon, 2013), also arranged by the International FH Foundation. The writing committee reexamined a pre-final draft of the paper and again reached full consensus on the recommendations of the guidance. GFW then prepared a final draft of the paper. All members approved the final document before submission. The recommendations and documents were also reviewed and fully endorsed by the National Lipid Association in August 2013. 


\section{Acknowledgements}

We thank the following experts for completing a brief questionnaire regarding contentious issues in FH: Pascale Benlian; Deepak Bhatnagar; Dirk Blom; Alberico Catapano; Richard Ceska; Ada Cuevas; John Deanfield; Olivier Descamps; Mats Eriksson; Claude Gagne; Anne Goldberg; Paul Hopkins David Marais; Luis Masana; Andre Miserez; Jonathan Morrell; Dermot Neely; Leiv Ose; Henry Purcell; Alan Rees; Handrean Soran; Mario Stoll; Charles Van Heyningen; Kurt Widhalm.

\section{Disclosures}

Some members of the Group have received lecture honoraria, consultancy fees, and/or research funding from: Abbrie (PPT); Abbott (GFW, KKL, KGP, RDS, AVS, BT); Aegerion (WVB,EB, ML, PM, KGP, RDS, JK); Alnylam Pharma (JK); Atherotech (PPT); Amarin Pharma (GFW, PPT, AVS, JK); Amgen (GFW, PPT, WVB, EB, KGP, FJR, RDS, DRS, AVS, BT, JK); AMT (EB); Astra Zeneca (GFW, PPT, WVB, EB, JD, KKL, FJR, RDS, WGS, DRS, AVS, BT, SY, EJGS; JK); Astellas (SY); AtheroNova Inc (JK); Bayer Yakuhin (SY); Biolab (RDS); Boehringer Ingelheim (KGP, EJGS, BT, SY, JK); Bristol Myers Squibb (WVB, KGP, RDS, BT, JK); Catabasis Pharma (WVB, JK); Cedus (EB); Cerenis Therapeutics S.A. (WVB, JK); CSL Behring LLC (JK); Danone (EB); Dezima (JK); Eli Lilly (JK); Forbion Capital Partners Inc (JK); Gedeon-Richter (AVS); Genentech (JK); Genfit (GFW, EB); Genzyme (GFW, PPT, RA, WVB, EB, ML, KGP, FJR, RDS, EJGS, WGS, AVS, BT, JK); GlaxoWelcome (WVB); GlaxoSmithKline (SG, EB, BT); Hoffman-La Roche (AW, JK); Isis Pharma (FJR, RDS, JK); INC Research LLC (JK); Janssen (BT); Kaken Pharma (SY); Kinemed (JK); Kissei Pharma (SY); Kowa (GFW, KGP, PPT, SY); Kyowa Medex (SY); Lilly (RDS); Liposcience (PPT, WVB); LPS Advisor Inc (JK); Medpace Inc (JK); Menarini (WGS); Merck Seron (BT); Merck Sharp \& Dohme (GFW, SG, RA, WVB, KKL, KGP, FJR, RDS, EJGS, WGS, DRS, AVS, BT, SY, JK); Mochida Pharma (SY); Novartis (GFW, EB, KKL, KGP, AVS, BT, JK); Omthera Pharma (AVS, JK); Ono Pharma (SY); Otsuka (SY); Pfizer (WVB, KKL, KGP, FJR, RDS, EJGS, DRS, AVS, SY, JK); 
Pronova Biopharma Norge A.S. (JK); Ranbaxy (BT); Randox (WGS);

Regeneron Pharma (ML, JD, JK); Resverlogix (JK); Roche (GFW, EB, KGP, WGS, DRS, BT); Sanofi (GFW, RA, WVB, EB, KKL, ML, PM, KGP, FJR, RDS, DRS, AVS, JK); Servier (BT); Siemens (WGS); Shionogi (SY); Sticares Cardiovascular Research Foundation (JK); Synexus Ltd (JK); Takeda (BT, SY); Teijin (SY); Vascular Research Network (JD); The Medicines Company (JK); UniQure Inc (JK); Vascular BioGenics Ltd (JK); Xenon Pharma (JK). 
- British Heart Foundation

www.bhf.org.uk

Leading British foundation provides excellent resources for health professionals and patients, including informative videos on a wide spectrum of conditions and risk factors.

- FH Australasia Network, Australian Atherosclerosis Society www.athero.org.au/FH

Website of the FH Australasia Network providing educational material and support for patients and health professionals caring for $\mathrm{FH}$. An integrated model of care for GPs that facilitates screening, diagnosis and referral pathways is included. The FH Network is currently working to create a unique web-based FH Registry that could be linked internationally.

- FHChol Austria, Austrian FH Patient Organisation www.fhchol.at Austrian patient support organization that provides support information and education for patients and families on all aspects of the detection and management of $\mathrm{FH}$.

- FH Guideline Implementation Team Toolkit www.heartuk.org.uk/FHToolkit Invaluable resource for implementing the seminal NICE guideline 71 on identification and management of $\mathrm{FH}$.

- FH Norway, Norwegian FH Patient Organisation www.f-h.no

Norwegian patient support organization that provides support information and education for patients and families on all aspects of the detection and management of $\mathrm{FH}$. 
- FH Support Group of Western Australia

www.fhfamilysupportgroup.websyte.com.au

Website of the first support group in Australia for families with $\mathrm{FH}$; provides relevant information, communication and support services.

- FH Portugal, Portugese FH Patient Organisation www.fhportugal.pt

Portugese patient support organization that provides support information and education for patients and families on all aspects of the detection and management of $\mathrm{FH}$.

- Foundation for the Identification of Persons with Inherited Hypercholesterolaemia (StoEH)

www.stoeh.nl

Premier organization for case detection in The Netherlands that promotes essential information for patients with $\mathrm{FH}$; to be reviewed in association with general information on CVD (www.hartenvaatgroup.nl); www.jojogenetics provides full guidance on DNA Testing for healthcare providers.

\section{- German FH Patient Organization}

www.cholco.org

German organization that provides support information and education for patients and families with $\mathrm{FH}$, as well as for health professionals and policy makers.

- HEART UK

www.heartuk.org.uk

Leading UK cholesterol charity that provides extensive resources for health professionals, patients and families on all aspects of the detection and management of $\mathrm{FH}$. 


\section{- Hipercol Brasil}

www.hipercolesterolemia.com.br

Website for $\mathrm{FH}$ patients and health professionals maintained by the Heart Institute (InCor), University of Sao Paulo Medical School Hospital; provides information about $\mathrm{FH}$ in the Portuguese language concerning how to screen and make a clinical and genetic diagnosis of $\mathrm{FH}$ in Brazil.

\section{- Human Genetics Society of Australasia}

\section{www.hgsa.org.au}

Premier Australasian society that provides educational materials, training, polices, guidelines and position statements on all aspects of human genetics.

- International FH Foundation

www.fh-foundation.org

Foundation, formed from the merger of MEDPED-International and HEART-EU, that has a vision of a world in which $\mathrm{FH}$ is routinely screened for and treated. Provides key support for patients, families, researchers and health professionals.

- Japan Atherosclerosis Society

www.j-athero.org

Information in Japanese on $\mathrm{FH}$ for both patients and general practitioners; to be reviewed in association with website for the patient association www.apheresis.web.fe2.com.

- Learn Your Lipids, NLA

www.learnyourlipids.com

Information for patients with dyslipidaemia, including $\mathrm{FH}$, as provided by the foundation of the National Lipid Association in the US. 


\section{- Lipids Online, Baylor College of Medicine}

www.lipidsonline.org

Established on-line facility, coordinated by Baylor College of Medicine (Houston, Texas, US), providing resources (slides, visual meetings, commentaries), for clinicians, researches and educators on several aspects of dyslipidaemia, atherosclerosis and cardiovascular disease.

- Make Early Diagnosis Prevent Early Death (MEDPED) FH www.medped.org

US based website of the original MEDPED Project coordinated by the University of Utah School of Medicine (Salt Lake City, Utah, US) focusing on all aspects of the management of $\mathrm{FH}$, including education of patients and families and the first attempt at establishing a US registry.

- National Genome Research Institute, National Institutes of Health www.genome.gov/25520184

General information on $\mathrm{FH}$.

www.genome.gov/11510372

Clinical useful tools for evaluating family history. www.genome.gov/11510371

Informative resources on general genetics for all health professionals.

- National Heart Foundation, Australia www.heartfoundation.org.au

Leading Australian charity that provides a wealth of resources for health professionals and the community on all aspects of primary and secondary prevention of cardiovascular disease.

- National Lipid Association (NLA), US

www.lipid.org

US based multidisciplinary specialty society providing education, training, guidelines and position statements on all aspects of the detection and management of dyslipidaemia and related disorders. 


\section{- New Zealand Guidelines Group}

www.nzgg.org.nz

New Zealand group of experts that specialises in developing and implementing guidelines for best clinical practice; excellent resources on the assessment and management of all cardiovascular risk factors.

\section{- The FH Foundation}

www.thefhfoundation.org

Patient centred foundation in US dedicated to raising awareness of $\mathrm{FH}$ through education, advocacy and research; currently working to establish the first comprehensive national FH Registry, with a launch in 2013.

\section{- Spanish FH Foundation}

www.colesterolfamiliar.org

An exemplary foundation providing support and education for patients and families with $\mathrm{FH}$, as well as for health professionals and policy makers; also includes a national registry for research and audit purposes.

\section{- Preventive Cardiovascular Nurses Association (PCNA)} www.pcna.net/patients/familial-hypercholesterolemia The US based PCNA provides information on meetings, online education, advocacy and news on cardiovascular risk prevention relevant to $\mathrm{FH}$. A useful patient tearsheet on essentials of $\mathrm{FH}$ suitable for people in different countries is available.

\section{- Public Health Genomics Foundation, UK} www.phgfoundation.org International foundation that publishes authoritative reports on the role of advances in genomics in health care; has a particularly excellent document on services for inherited cardiovascular conditions. 
- Wales FH Testing Service, Cardiff University

www.fhwales.co.uk

Leading $\mathrm{FH}$ service in the UK that provides useful information and resources for clinical practice, including activities of FH Family Forum. 
[1] Austin MA, Hutter CM, Zimmern RL, Humphries SE. Genetic causes of monogenic heterozygous familial hypercholesterolaemia: A HuGE prevalence review. Am J Epidemiol. 2004;160:407-20.

[2] Soutar AK, Naoumova RP. Mechanisms of Disease: genetic causes of familial hypercholesterolemia. Nat Clin Pract Cardiovasc Med. 2007;4:214-25.

[3] Marks D, Thorogood M, Neil HAW, Humphries SE. A review on the diagnosis, natural history, and treatment of familial hypercholesterolaemia. Atherosclerosis. 2003;168:1-14.

[4] World Health Organization. Familial Hypercholesterolaemia: Report of a WHO consultation. Paris: World Health Organisation; 1997.

[5] Umans-Eckenhausen MAW, Defesche JC, Sijbrands EJG, Scheerder RLJM, Kastelein JJP. Review of first 5 years of screening for familial hypercholesterolaemia in the Netherlands. Lancet. 2001;357:165-8.

[6] National Institute for Health and Clinical Excellence, The National Collaborating Centre for Primary Care. NICE Clinical Guideline 71: Identification and management of familial hypercholesterolaemia. 2008.

[7] Civeira F. Guidelines for the diagnosis and management of heterozygous familial hypercholesterolaemia. Atherosclerosis. 2004;173:55-68.

[8] Watts GF, Sullivan DR, Poplawski N, van Bockxmeer F, Hamilton-Craig I, Clifton

PM, et al. Familial hypercholesterolaemia: A model of care for Australasia.

Atherosclerosis Supplements. 2011;12:221-63.

[9] Goldberg AC, Hopkins PN, Toth PP, Ballantyne CM, Rader DJ, Robinson JG, et al. Familial Hypercholesterolemia: Screening, diagnosis and management of pediatric and adult patients: Clinical guidance from the National Lipid Association Expert Panel on Familial Hypercholesterolemia. J Clin Lipidol. 2011;5:133-40. [10] National Cholesterol Education Program (NCEP). Third Report of the National Cholesterol Education Program (NCEP) Expert Panel on Detection, Evaluation, and Treatment of High Blood Cholesterol in Adults (Adult Treatment Panel III) Final Report. Circulation. 2002;106:3143-421.

[11] Perk J, De Backer G, Gohlke H, Graham I, Reiner Ž, Verschuren M, et al. European Guidelines on cardiovascular disease prevention in clinical practice (version 2012) The Fifth Joint Task Force of the European Society of Cardiology and Other Societies on Cardiovascular Disease Prevention in Clinical Practice (constituted by representatives of nine societies and by invited experts) Developed with the special contribution of the European Association for Cardiovascular Prevention \& Rehabilitation (EACPR). Eur Heart J. 2012;33:1635-701. [12] Brunzell JD, Davidson M, Furberg CD, Goldberg RB, Howard BV, Stein JH, et al. Lipoprotein Management in Patients With Cardiometabolic Risk. Diabetes Care. 2008;31:811-22.

[13] Reiner Z, Catapano AL, De Backer G, Graham I, Taskinen MR, Wiklund O, et al. ESC/EAS Guidelines for the management of dyslipidaemias The Task Force for the management of dyslipidaemias of the European Society of Cardiology (ESC) and the European Atherosclerosis Society (EAS). Eur Heart J. 2011;32:1769-818.

[14] International Atherosclerosis Society. IAS Position Paper: Global Recommendations for the Management of Dyslipidemia. 2013.

[15] Nordestgaard BG, Chapman MJ, Humphries SE, Ginsberg HN, Masana L, Descamps OS, et al. Familial hypercholesterolaemia is underdiagnosed and undertreated in the general population: guidance for clinicians to prevent coronary 
heart disease Consensus Statement of the European Atherosclerosis Society. Eur Heart J. 2013:1-14.

[16] Santos RD, Gagliardi ACM, Xavier HT, Casella Filho A, Araujo DB, Casena FY, et al. Brazilian Guidelines to Familial Hypercholesterolaemia (FH). Arq Bras Cardiol. 2012;99:1-28.

[17] Neil HAW, Hammond T, Huxley R, Matthews DR, Humphries SE. Extent of underdiagnosis of familial hypercholesterolaemia in routine practice: prospective registry study. Br Med J. 2000;321:148.

[18] Pijlman AH, Huijgen R, Verhagen SN, Imholz BPM, Liem AH, Kastelein JJP, et al. Evaluation of cholesterol lowering treatment of patients with familial hypercholesterolemia: a large cross-sectional study in The Netherlands.

Atherosclerosis. 2010;209:189-94.

[19] Descamps OS, Tenoutasse S, Stephenne X, Gies I, Beauloye V, Lebrethon MC, et al. Management of familial hypercholesterolemia in children and young adults:

Consensus paper developed by a panel of lipidologists, cardiologists, paediatricians, nutritionists, gastroenterologists, general practitioners and a patient organization.

Atherosclerosis. 2011;218:272-80.

[20] Daniels SR, Gidding SS, de Ferranti SD. Pediatric aspects of Familial

Hypercholesterolemias: Recommendations from the National Lipid Association

Expert Panel on Familial Hypercholesterolemia. J Clin Lipidol. 2011;5:S30-S7.

[21] Kusters DM, de Beaufort C, Widhalm K, Guardamagna O, Bratina N, Ose L, et al. Paediatric screening for hypercholesterolaemia in Europe. Arch Dis Child. 2012;97:272-6.

[22] Harada-Shiba M, Arai H, Oikawa S, Ohta T, Okada T, Okamura T, et al. Guidelines for the management of familial hypercholesterolemia. J Atheroscler Thromb. 2012;19:1043-60.

[23] World Health Organization. Building Blocks for Action Innovative Care for Chronic Conditions: Global Report. 2002.

[24] Morris JK, Wald DS, Wald NJ. The evaluation of cascade testing for familial hypercholesterolemia. American Journal of Medical Genetics Part A. 2011;158:78-

84.

[25] Bates TR, Burnett JR, van Bockxmeer FM, Hamilton S, Arnolda L, Watts GF.

Detection of familial hypercholesterolaemia: A major treatment gap in preventative cardiology. Heart Lung Circ. 2008;17:411-3.

[26] Scientific Steering Committee on behalf of the Simon Broome Register Group. Risk of fatal coronary heart disease in familial hypercholesterolaemia. . Br Med J. 1991;303:893-6.

[27] Kirke A, Watts GF, Emery J. Detecting familial hypercholesterolaemia in general practice. Aust Fam Physician. 2012;41:965-8.

[28] Qureshi N, Humphries SE, Seed M, Rowlands P, Minhas R, NICE Guideline

Development Group. Identification and management of familial

hypercholesterolaemia: what does it mean to primary care? $\mathrm{Br} \mathrm{J}$ Gen Pract.

2009;59:773-8.

[29] Tiyyagura SR, Smith DA. Standard lipid profile. Clin Lab Med. 2006;26:707-32.

[30] Bell DA, Hooper AJ, Bender R, McMahon J, Edwards G, van Bockxmeer FM, et

al. Opportunistic screening for familial hypercholesterolaemia via a community laboratory. Ann Clin Biochem. 2012;49:534-7.

[31] Datta BN, McDowell IF, Rees A. Integrating provision of specialist lipid services with cascade testing for familial hypercholesterolaemia. Curr Opin Lipidol.

2010;21:366-71. 
[32] Raal FJ, Santos RD. Homozygous familial hypercholesterolemia: Current perspectives on diagnosis and treatment. Atherosclerosis. 2012;223:262-8.

[33] HEART UK. FH Guideline Implementation Team Toolkit. 2010.

$<$ www.heartuk.org.uk>.

[34] World Health Organization. Familial Hypercholesterolaemia. Report of a second WHO Consultation. Geneva: World Health Organization; 1999.

[35] Williams RR, Hunt SC, Schumacher MC, Hegele RA, Leppert MF, Ludwig EH, et al. Diagnosing heterozygous familial hypercholesterolemia using new practical criteria validated by molecular genetics. Am J Cardiol. 1993;72:171-6.

[36] Chow CK, Islam S, Bautista L, Rumboldt Z, Yusufali A, Xie C, et al. Parental History and Myocardial Infarction Risk Across the World: The INTERHEART Study. J Am Coll Cardiol. 2011;57:619-27.

[37] Ritchie SK, Murphy EC-S, Ice C, Cottrell LA, Minor V, Elliott E, et al. Universal Versus Targeted Blood Cholesterol Screening Among Youth: The CARDIAC Project. Pediatrics. 2010;126:260-5.

[38] Niu D-M, Chong K-W, Hsu J-H, Wu TJ-T, Yu H-C, Huang C-H, et al. Clinical observations, molecular genetic analysis, and treatment of sitosterolemia in infants and children. J Inherit Metab Dis. 2010;33:437-43.

[39] Veerkamp MJ, de Graaf J, Hendriks JCM, Demacker PNM, Stalenhoef AFH. Nomogram to diagnose familial combined hyperlipidemia on the basis of results of a 5-year follow-up study. Circulation. 2004;109:2980-5.

[40] Carmena R, Roy M, Roederer G, Minnich A, Davignon J. Coexisting dysbetalipoproteinemia and familial hypercholesterolemia: Clinical and laboratory observations. Atherosclerosis. 2000;148:113-24.

[41] Ooi EMM, Barrett PHR, Watts GF. The extended abnormalities in lipoprotein metabolism in familial hypercholesterolemia: Developing a new framework for future therapies. Int $\mathrm{J}$ Cardiol. 2013:[Epub ahead of print].

[42] Jones PH, Davidson MH, Stein EA, Bays HE, McKenney JM, Miller E, et al. Comparison of the efficacy and safety of rosuvastatin versus atorvastatin, simvastatin, and pravastatin across doses (STELLAR Trial). Am J Cardiol. 2003;92:152-60.

[43] Jansen ACM, van Aalst-Cohen ES, Tanck MW, Trip MD, Lansberg PJ, Liem AH, et al. The contribution of classical risk factors to cardiovascular disease in familial hypercholesterolaemia: data in 2400 patients. J Intern Med. 2004;256:482-90. [44] Oosterveer DM, Versmissen J, Schinkel AF, Langendonk JG, Mulder M, Sijbrands EJ. Clinical and genetic factors influencing cardiovascular risk in patients with familial hypercholesterolemia. Clin Lipidol. 2010;5:189-97.

[45] Neefjes LA, Ten Kate G-JR, Rossi A, Galema-Boers AJ, Langendonk JG, Weustink $A C$, et al. CT coronary plaque burden in asymptomatic patients with familial hypercholesterolaemia. Heart. 2011;97:1151-7.

[46] Claassen L, Henneman L, Kindt I, Marteau TM, Timmermans DRM. Perceived Risk and Representations of Cardiovascular Disease and Preventive Behaviour in People Diagnosed with Familial Hypercholesterolemia. J Health Psychol. 2010;15:33-43.

[47] Marteau T, Senior V, Humphries SE, Bobrow M, Cranston T, Crook MA, et al. Psychological impact of genetic testing for familial hypercholesterolemia within a previously aware population: A randomized controlled trial. Am J Med Genet. 2004;128A:285-93. 
[48] Junyent M, Gilabert R, Jarauta E, Núñez I, Cofán M, Civeira F, et al. Impact of low-density lipoprotein receptor mutational class on carotid atherosclerosis in patients with familial hypercholesterolemia. Atherosclerosis. 2010;208:437-41. [49] Nordestgaard BG, Chapman MJ, Ray K, Borén J, Andreotti F, Watts GF, et al. Lipoprotein(a) as a cardiovascular risk factor: Current status. Eur Heart J. 2010;31:2844-53.

[50] Thanassoulis G, Campbell CY, Owens DS, Smith JG, Smith AV, Peloso GM, et al. Genetic Associations with Valvular Calcification and Aortic Stenosis. N Engl J Med. 2012;368:503-12.

[51] Lloyd-Jones DM. Cardiovascular Risk Prediction: Basic Concepts, Current Status, and Future Directions. Circulation. 2010;121:1768-77.

[52] Wiegman A, de Groot E, Hutten BA, Rodenburg J, Gort J, Bakker HD, et al. Arterial intima-media thickness in children heterozygous for familial hypercholesterolaemia. Lancet. 2004;363:369-70.

[53] Vuorio A, Doherty KF, Humphries SE, Kuoppala J, Kovanen PT. Statin treatment of children with familial hypercholesterolemia - trying to balance incomplete evidence of long-term safety and clinical accountability: are we approaching a consensus? Atherosclerosis. 2013;226:315-20.

[54] Greenland P, Alpert JS, Beller GA, Benjamin EJ, Budoff MJ, Fayad ZA, et al. 2010 ACCF/AHA Guideline for Assessment of Cardiovascular Risk in Asymptomatic Adults: A Report of the American College of Cardiology Foundation/American Heart Association Task Force on Practice Guidelines. Circulation. 2010;122:2748-64.

[55] Den Ruijter HM, Peters SAE, Anderson TJ, Britton AR, Dekker JM, Eijkemans MJ, et al. Common Carotid Intima-Media Thickness Measurements in Cardiovascular Risk PredictionA Meta-analysisCarotid Intima-Media Thickness and Risk Prediction. J Amer Med Assoc. 2012;308:796-803.

[56] Smilde TJ, van Wissen S, Wollersheim H, Trip MD, Kastelein JJ, Stalenhoef AF. Effect of aggressive versus conventional lipid lowering on atherosclerosis progression in familial hypercholesterolaemia (ASAP): a prospective, randomised, double-blind trial. Lancet. 2001;357:577-81.

[57] Clarke REJ, Padayachee ST, Preston R, McMahon Z, Gordon M, Graham C, et al. Effectiveness of alternative strategies to define index case phenotypes to aid genetic diagnosis of familial hypercholesterolaemia. Heart. 2013;99:175-80.

[58] Cho I, Chang H-J, Sung JM, Pencina MJ, Lin FY, Dunning AM, et al. Coronary Computed Tomographic Angiography and Risk of All-Cause Mortality and Nonfatal Myocardial Infarction in Subjects Without Chest Pain Syndrome From the CONFIRM Registry (Coronary CT Angiography Evaluation for Clinical Outcomes: An International Multicenter Registry) Clinical Perspective. Circulation. 2012;126:30413.

[59] Anderson TJ, Grégoire J, Hegele RA, Couture P, Mancini GB, McPherson R, et al. 2012 Update of the Canadian Cardiovascular Society Guidelines for the Diagnosis and Treatment of Dyslipidemia for the Prevention of Cardiovascular Disease in the Adult. Can J Cardiol. 2013;29:151-67.

[60] Huijgen R, Vissers MN, Kindt I, Trip MD, de Groot E, Kastelein JJP, et al. Assessment of carotid atherosclerosis in normocholesterolemic individuals with proven mutations in the low-density lipoprotein receptor or apolipoprotein B genes. Circulation: Cardiovascular Genetics. 2011;4:413-7.

[61] Michos ED, Nasir K, Rumberger JA, Vasamreddy C, Braunstein JB, Budoff MJ, et al. Relation of family history of premature coronary heart disease and metabolic 
risk factors to risk of coronary arterial calcium in asymptomatic subjects. Am J Cardiol. 2005;95:655-7.

[62] Engelen L, Ferreira I, Stehouwer CD, Boutouyrie P, Laurent Sp, Jouven X, et al. Reference intervals for common carotid intima-media thickness measured with echotracking: relation with risk factors. Eur Heart J. 2013.

[63] Sijbrands E, Westendorp R, Defesche J, de Meier P, Smelt A, Kastelein J, et al. Mortality over two centuries in large pedigree with familial hypercholesterolaemia: family tree mortality study. Br Med J. 2001;322:1019-23.

[64] Thompson GR, Catapano A, Saheb S, Atassi-Dumont M, Barbir M, Eriksson M, et al. Severe hypercholesterolaemia: therapeutic goals and eligibility criteria for LDL apheresis in Europe. Curr Opin Lipidol. 2010;21:492-8.

[65] Martin AC, Coakley J, Forbes DA, Sullivan DR, Watts GF. Familial hypercholesterolaemia in children and adolescents: A new paediatric model of care. J Paediatr Child Health. 2013;49:E263-E72.

[66] McCrindle BW. Familial hypercholesterolemia in children and adolescents. Curr Opin Lipidol. 2012;23:525-31.

[67] Wiegman A, Rodenburg J, de Jongh S, Defesche JC, Bakker HD, Kastelein JJP, et al. Family history and cardiovascular risk in familial hypercholesterolemia data in more than 1000 children. Circulation. 2003;107:1473-8.

[68] van der Graaf A, Avis HJ, Kusters DM, Vissers MN, Hutten BA, Defesche JC, et al. Molecular Basis of Autosomal Dominant Hypercholesterolemia: Assessment in a Large Cohort of Hypercholesterolemic Children. Circulation. 2011;123:1167-73. [69] Langslet G, Ose L. Screening methods in the diagnosis and assessment of children and adolescents with familial hypercholesterolemia. Expert Rev Cardiovasc Ther. 2013;11:1061-6.

[70] Starr B, Hadfield G, Hutton BA, Lansberg PJ, Leren TP, Damgaard D, et al. Development of sensitive and specific age-and gender-specific low-density lipoprotein cholesterol cutoffs for diagnosis of first-degree relatives with familial hypercholesterolaemia in cascade testing. Clin Chem Lab Med. 2008;46:791-803. [71] Wald DS, Bestwick JP, Wald NJ. Child-parent screening for familial hypercholesterolaemia: Screening strategy based on a meta-analysis. Br Med J. 2007;335:599-603.

[72] Freedman DS, Wang YC, Dietz WH, Xu J-H, Srinivasan SR, Berenson GS. Changes and Variability in High Levels of Low-Density Lipoprotein Cholesterol Among Children. Pediatrics. 2010;126:266-73.

[73] Kavey R-EW, Allada V, Daniels SR, Hayman LL, McCrindle BW, Newburger JW, et al. Cardiovascular Risk Reduction in High-Risk Pediatric Patients: A Scientific Statement From the American Heart Association Expert Panel on Population and Prevention Science; the Councils on Cardiovascular Disease in the Young, Epidemiology and Prevention, Nutrition, Physical Activity and Metabolism, High Blood Pressure Research, Cardiovascular Nursing, and the Kidney in Heart Disease; and the Interdisciplinary Working Group on Quality of Care and Outcomes Research. Circulation. 2006;114:2710-38.

[74] Gidding SS, Bookstein LC, Chomka EV. Usefulness of electron beam tomography in adolescents and young adults with heterozygous familial hypercholesterolemia. Circulation. 1998;98:2580-3.

[75] Urbina EM, Williams RV, Alpert BS, Collins RT, Daniels SR, Hayman L, et al. Noninvasive Assessment of Subclinical Atherosclerosis in Children and Adolescents: Recommendations for Standard Assessment for Clinical Research: A Scientific Statement From the American Heart Association. Hypertension. 2009;54:919-50. 
[76] Marks D, Wonderling D, Thorogood M, Lambert H, Humphries SE, Neil HAW. Cost effectiveness analysis of different approaches of screening for familial hypercholesterolaemia. Br Med J. 2002;324:1303-9.

[77] Ademi Z, Watts GF, Juniper A, Liew D. A systematic review of economic evaluations of the detection and treatment of familial hypercholesterolemia. Int $\mathrm{J}$ Cardiol. 2013;167:2391-6.

[78] Humphries SE, Norbury G, Leigh S, Hadfield SG, Nair D. What is the clinical utility of DNA testing in patients with familial hypercholesterolaemia? Curr Opin Lipidol. 2008;19:362-8.

[79] Suthers GK, Armstrong J, McCormack J, Trott D. Letting the family know: balancing ethics and effectiveness when notifying relatives about genetic testing for a familial disorder. J Med Genet. 2006;43:665-70.

[80] Hadfield SG, Horara S, Starr BJ, Yazdgerdi S, Marks D, Bhatnagar D, et al. Family tracing to identify patients with Familial Hypercholesterolaemia: the second Audit of the Department of Health Familial Hypercholesterolaemia Cascade Testing Project. Ann Clin Biochem. 2009;46:24-32.

[81] Neil HAW, Hammond T, Mant D, Humphries SE. Effect of statin treatment for familial hypercholesterolaemia on life assurance: results of consecutive surveys in 1990 and 2002. Br Med J. 2004;328:500-1.

[82] Hollands G, Armstrong D, Macfarlane A, Crook M, Marteau T. Patient accounts of diagnostic testing for familial hypercholesterolaemia: comparing responses to genetic and non-genetic testing methods. BMC Medical Genetics. 2012;13:87. [83] Suthers GK, McCusker EA, Wake SA. Alerting genetic relatives to a risk of serious inherited disease without a patient's consent. Med J Aust. 2011;194:385-6. [84] Taylor A, Wang D, Patel K, Whittall R, Wood G, Farrer M, et al. Mutation detection rate and spectrum in familial hypercholesterolaemia patients in the UK pilot cascade project. Clin Genet. 2010;77:572-80.

[85] Lombardi MP, Redeker EJW, van Gent DHM, Smeele KL, Weederstein R, Mannens MM. Molecular genetic testing for familial hypercholesterolaemia in the Netherlands: a stepwise screening strategy enhances the mutation detection rate. Genet Test. 2006;10:77-84.

[86] Hooper AJ, Nguyen LT, Burnett JR, Bates TR, Bell DA, Redgrave TG, et al. Genetic analysis of familial hypercholesterolaemia in Western Australia.

Atherosclerosis. 2012;224:430-4.

[87] Motazacker MM, Pirruccello J, Huijgen R, Do R, Gabriel S, Peter J, et al. Advances in genetics show the need for extending screening strategies for autosomal dominant hypercholesterolaemia. Eur Heart J. 2012;33:1360-6. [88] Ahmad Z, Adams-Huet B, Chen C, Garg A. Low prevalence of mutations in known loci for autosomal dominant hypercholesterolemia in a multiethnic patient cohort. Circulation: Cardiovascular Genetics. 2012;5:666-75.

[89] Talmud PJ, Shah S, Whittall R, Futema M, Howard P, Cooper JA, et al. Use of low-density lipoprotein cholesterol gene score to distinguish patients with polygenic and monogenic familial hypercholesterolaemia: a case-control study. The Lancet. 2013;381:13-9.

[90] Nherera L, Marks D, Minhas R, Thorogood M, Humphries SE. Probabilistic costeffectiveness analysis of cascade screening for familial hypercholesterolaemia using alternative diagnostic and identification strategies. Heart. 2011;97:1175-81.

[91] European Society of Human Genetics. Genetic testing in asymptomatic minors: recommendations of the European Society of Human Genetics. Eur J Hum Genet. 2009;17:720-1. 
[92] Khoury MJ, Coates RJ, Evans JP. Evidence-based classification of recommendations on use of genomic tests in clinical practice: dealing with insufficient evidence. Genet Med. 2010;12:680-3.

[93] National Institute for Health and Clinical Excellence. Elucigene FH20 and LIPOchip for the diagnosis of familial hypercholesterolaemia. 2011.

[94] Taylor A, Martin B, Wang D, Patel K, Humphries SE, Norbury G. Multiplex ligation-dependent probe amplification analysis to screen for deletions and duplications of the LDLR gene in patients with familial hypercholesterolaemia. Clin Genet. 2009;76:69-75.

[95] Usifo E, Leigh SEA, Whittall RA, Lench N, Taylor A, Yeats C, et al. Low-Density Lipoprotein Receptor Gene Familial Hypercholesterolemia Variant Database: Update and Pathological Assessment. Ann Hum Genet. 2012;76:387-401.

[96] Robinson JG, Goldberg AC. Treatment of adults with Familial

Hypercholesterolemia and evidence for treatment: Recommendations from the National Lipid Association Expert Panel on Familial Hypercholesterolemia. J Clin Lipidol. 2011;5:S18-S29.

[97] Watts GF, Juniper A, van Bockxmeer F, Ademi Z, Liew D, O'Leary P. Familial hypercholesterolaemia: a review with emphasis on evidence for treatment, new models of care and health economic evaluations. Int J Evid Based Healthc. 2012;10:211-21.

[98] Chapman MJ, Ginsberg HN, Amarenco P, Andreotti F, Borén J, Catapano AL, et al. Triglyceride-rich lipoproteins and high-density lipoprotein cholesterol in patients at high risk of cardiovascular disease: evidence and guidance for management. Eur Heart J. 2011.

[99] Broekhuizen K, Gm JJ, Mireille van Poppel NM, Lj LK, Brug J, van Mechelen W. Is the process of delivery of an individually tailored lifestyle intervention associated with improvements in LDL cholesterol and multiple lifestyle behaviours in people with Familial Hypercholesterolemia? BMC Public Health. 2012;12:348.

[100] Lichtenstein AH, Appel LJ, Brands M, Carnethon M, Daniels S, Franch HA, et al. Diet and Lifestyle Recommendations Revision 2006: A Scientific Statement From the American Heart Association Nutrition Committee. Circulation. 2006;114:82-96. [101] Gidding SS, Lichtenstein AH, Faith MS, Karpyn A, Mennella JA, Popkin B, et al. Implementing American Heart Association Pediatric and Adult Nutrition Guidelines: A Scientific Statement From the American Heart Association Nutrition Committee of the Council on Nutrition, Physical Activity and Metabolism, Council on Cardiovascular Disease in the Young, Council on Arteriosclerosis, Thrombosis and Vascular Biology, Council on Cardiovascular Nursing, Council on Epidemiology and Prevention, and Council for High Blood Pressure Research. Circulation.

2009;119:1161-75.

[102] Artinian NT, Fletcher GF, Mozaffarian D, Kris-Etherton P, Van Horn L, Lichtenstein $\mathrm{AH}$, et al. Interventions to Promote Physical Activity and Dietary Lifestyle Changes for Cardiovascular Risk Factor Reduction in Adults: A Scientific Statement From the American Heart Association. Circulation. 2010;122:406-41. [103] Estruch R, Ros E, Salas-Salvadó J, Covas M-I, Corella D, Arós F, et al. Primary prevention of cardiovascular disease with a Mediterranean diet. N Engl J Med. 2013;368:1279-90.

[104] Moruisi KG, Oosthuizen W, Opperman AM. Phytosterols/Stanols Lower Cholesterol Concentrations in Familial Hypercholesterolemic Subjects: A Systematic Review with Meta-Analysis. J Am Coll Nutr. 2006;25:41-8. 
[105] Mancia G, Fagard R, Narkiewicz K, Redon J, Zanchetti A, Böhm M, et al. 2013 ESH/ESC Guidelines for the management of arterial hypertension: The Task Force for the management of arterial hypertension of the European Society of Hypertension (ESH) and of the European Society of Cardiology (ESC). Blood Press. 2013;22:193-278.

[106] Descamps OS, de Meester A, Cheron P, Kastelein JJ, Heller FR. Silent ischaemia in familial hypercholesterolemia. Atherosclerosis Supplements. 2003;4:78.

[107] Haas L, Maryniuk M, Beck J, Cox CE, Duker P, Edwards L, et al. National standards for diabetes self-management education and support. Diabetes Care. 2013;36:S100-S8.

[108] Cholesterol Treatment Trialists' (CTT) Collaboration. Efficacy and safety of more intensive lowering of LDL cholesterol: a meta-analysis of data from 170000 participants in 26 randomised trials. Lancet. 2010;376:1670-81.

[109] Versmissen J, Oosterveer DM, Yazdanpanah M, Defesche JC, Basart DCG, Liem $\mathrm{AH}$, et al. Efficacy of statins in familial hypercholesterolaemia: a long term cohort study. Br Med J. 2008;337:a2423.

[110] Neil A, Cooper J, Betteridge J, Capps N, McDowell I, Durrington P, et al. Reductions in all-cause, cancer, and coronary mortality in statin-treated patients with heterozygous familial hypercholesterolaemia: a prospective registry study. Eur Heart J. 2008;29:2625-33.

[111] Harada-Shiba M, Sugisawa T, Makino H, Abe M, Tsushima M, Yoshimasa $Y$, et al. Impact of statin treatment on the clinical fate of heterozygous familial hypercholesterolemia. J Atheroscler Thromb. 2010;17:667-74.

[112] Raal FJ, Pilcher GJ, Panz VR, van Deventer HE, Brice BC, Blom DJ, et al. Reduction in Mortality in Subjects With Homozygous Familial Hypercholesterolemia Associated With Advances in Lipid-Lowering Therapy. Circulation. 2011;124:2202-7. [113] Elis A, Zhou R, Stein EA. Effect of lipid-lowering treatment on natural history of heterozygous familial hypercholesterolemia in past three decades. The American Journal of Cardiology. 2011;108:223-6.

[114] Alonso R, Fernandez de Bobadilla J, Mendez I, Lazaro P, Mata N, Mata P. Cost-effectiveness of managing familial hypercholesterolemia using atorvastatinbased preventive therapy. Rev Esp Cardiol. 2008;61:382-93.

[115] Nherera L, Calvert NW, DeMott K, Humphries SE, Neil HAW, Minhas R, et al. Cost-effectiveness analysis of the use of a high-intensity statin compared to a lowintensity statin in the management of patients with familial hypercholesterolaemia. Curr Med Res Opin. 2010;26:529-36.

[116] National Institute for Health and Clinical Excellence. Ezetimibe for the treatment of primary (heterozygous-familial and non-familial) hypercholesterolaemia. NICE technology appraisal guidance 1322010.

[117] Hamilton-Craig I, Kostner K, Colquhoun D, Woodhouse S. Combination therapy of statin and ezetimibe for the treatment of familial hypercholesterolaemia. Vasc Health Risk Manag. 2010;6:1023-37.

[118] Toth PP. Drug Treatment of Hyperlipidaemia: A Guide to the Rational Use of Lipid-Lowering Drugs. Drugs. 2010;70:1363-79.

[119] Chapman MJ, Redfern JS, McGovern ME, Giral P. Niacin and fibrates in atherogenic dyslipidemia: Pharmacotherapy to reduce cardiovascular risk.

Pharmacol Ther. 2010;126:314-45. 
[120] Kane JP, Malloy MJ, Ports TA, Phillips NR, Diehl JC, Havel RJ. Regression of Coronary Atherosclerosis During Treatment of Familial Hypercholesterolemia With Combined Drug Regimens. J Amer Med Assoc. 1990;264:3007-12.

[121] Yamashita S, Matsuzawa Y. Where are we with probucol: A new life for an old drug? Atherosclerosis. 2009;207:16-23.

[122] Gagné C, Gaudet D, Bruckert E. Efficacy and safety of ezetimibe coadministered with atorvastatin or simvastatin in patients with homozygous familial hypercholesterolemia. Circulation. 2002;105:2469-75.

[123] Cuchel M, Meagher EA, du Toit Theron H, Blom DJ, Marais AD, Hegele RA, et al. Efficacy and safety of a microsomal triglyceride transfer protein inhibitor in patients with homozygous familial hypercholesterolaemia: a single-arm, open-label, phase 3 study. The Lancet. 2013;381:40-6.

[124] Raal FJ, Santos RD, Blom DJ, Marais AD, Charng M-J, Cromwell WC, et al. Mipomersen, an apolipoprotein B synthesis inhibitor, for lowering of LDL cholesterol concentrations in patients with homozygous familial hypercholesterolaemia: a randomised, double-blind, placebo-controlled trial. Lancet. 2010;375:998-1006. [125] Bates TR, Connaughton VM, Watts GF. Non-adherence to statin therapy: a major challenge for preventive cardiology. Expert Opin Pharmacother. 2009;10:2973-85.

[126] Senior V, Marteau T, Weinman J. Self-Reported Adherence to CholesterolLowering Medication in Patients with Familial Hypercholesterolaemia: The Role of IIIness Perceptions. Cardiovasc Drugs Ther. 2004;18:475-81.

[127] McKenney JM, Davidson MH, Jacobson TA, Guyton JR. Final conclusions and recommendations of the national lipid association statin safety assessment task force. The American Journal of Cardiology. 2006;97:S89-S94.

[128] Ridker PM, Pradhan A, MacFadyen JG, Libby P, Glynn RJ. Cardiovascular benefits and diabetes risks of statin therapy in primary prevention: an analysis from the JUPITER trial. The Lancet. 2012;380:565-71.

[129] Thompson PD, Clarkson PM, Rosenson RS. An assessment of statin safety by muscle experts. The American Journal of Cardiology. 2006;97:S69-S76.

[130] Venero CV, Thompson PD. Managing statin myopathy. Endocrinol Metab Clin North Am. 2009;38:121-36.

[131] Eckel RH. Approach to the Patient Who Is Intolerant of Statin Therapy. J Clin Endocrinol Metab. 2010;95:2015-22.

[132] Davidson MH, Armani A, McKenney JM, Jacobson TA. Safety Considerations with Fibrate Therapy. Am J Cardiol. 2007;99:S3-S18.

[133] Bottorff MB. Statin Safety and Drug Interactions: Clinical Implications. Am J Cardiol. 2006;97:S27-S31.

[134] Mampuya WM, Frid D, Rocco M, Huang J, Brennan DM, Hazen SL, et al. Treatment strategies in patients with statin intolerance: The Cleveland Clinic experience. Am Heart J. 2013;166:597-603.

[135] Guyton JR, Goldgerg AC. Bile Acid Sequestrants. In: Ballantyne CM, editor. Clinical Lipidology: a Companion to Braunwald's Heart Disease. Philadelphia:

Saunders Elsevier; 2009. p. 281-314.

[136] Guyton JR, Bays HE. Safety Considerations with Niacin Therapy. Am J Cardiol. 2007;99:S22-S31.

[137] Haynes R, Jiang L, Hopewell JC, Li J, Chen F, Parish S, et al. HPS2-THRIVE randomized placebo-controlled trial in 25673 high-risk patients of ER

niacin/laropiprant: trial design, pre-specified muscle and liver outcomes, and reasons for stopping study treatment. Eur Heart J. 2013;34:1279-91. 
[138] Thorogood M, Seed M, De Mott K, Guideline Development Group.

Management of fertility in women with familial hypercholesterolaemia: summary of NICE guidance. Br J Obstet Gynaecol. 2009;116:478-9.

[139] Lidegaard Ø, Løkkegaard E, Jensen A, Skovlund CW, Keiding N. Thrombotic stroke and myocardial infarction with hormonal contraception. $\mathrm{N}$ Engl J Med. 2012;366:2257-66.

[140] Kusters DM, Lahsinoui HH, van de Post JAM, Wiegman A, Wijburg FA, Kastelein JJP, et al. Statin use during pregnancy: a systematic review and metaanalysis. Expert Rev Cardiovasc Ther. 2012;10:363-78.

[141] van der Graaf A, Vissers MN, Gaudet D, Brisson D, Sivapalaratnam S, Roseboom TJ, et al. Dyslipidemia of Mothers With Familial Hypercholesterolemia Deteriorates Lipids in Adult Offspring. Arterioscler Thromb Vasc Biol. 2010;30:26737.

[142] Ito MK, McGowan MP, Moriarty PM. Management of Familial

Hypercholesterolemias in adult patients: Recommendations from the National Lipid Association Expert Panel on Familial Hypercholesterolemia. 2011;5:S38-S45.

[143] Santen RJ, Allred DC, Ardoin SP, Archer DF, Boyd N, Braunstein GD, et al. Postmenopausal hormone therapy: an Endocrine Society scientific statement. J Clin Endocrinol Metab. 2010;95:s1-s66.

[144] Løkkegaard E, Andreasen AH, Jacobsen RK, Nielsen LH, Agger C, Lidegaard $\varnothing$. Hormone therapy and risk of myocardial infarction: a national register study. Eur Heart J. 2008;29:2660-8.

[145] Rodenburg J, Vissers MN, Wiegman A, van Trotsenburg ASP, van der Graaf

A, de Groot E, et al. Statin Treatment in Children With Familial

Hypercholesterolemia: The Younger, the Better. Circulation. 2007;116:664-8.

[146] Avis HJ, Vissers MN, Stein EA, Wijburg FA, Trip MD, Kastelein JJP, et al. A

Systematic Review and Meta-Analysis of Statin Therapy in Children With Familial Hypercholesterolemia. Arterioscler Thromb Vasc Biol. 2007;27:1803-10.

[147] Vuorio A, Kuoppala J, Kovanen PT, Humphries SE, Strandberg T, Tonstad S, et al. Statins for children with familial hypercholesterolemia. Cochrane Database Syst Rev. 2010;Issue 7. Art. No.: CD006401.

[148] McCrindle BW, Urbina EM, Dennison BA, Jacobson MS, Steinburger J, Rocchini AP, et al. Drug therapy of high risk lipid abnormalities in children and adolescents. Circulation. 2007;115:1-20.

[149] Braamskamp MJAM, Wijburg FA, Wiegman A. Drug Therapy of

Hypercholesterolaemia in Children and Adolescent. Drugs. 2012;72:759-72.

[150] Hammond E, Watts GF, Rubinstein Y, Farid W, Livingston M, Knowles JW, et al. Role of international registries in enhancing the care of familial hypercholesterolaemia. Int J Evid Based Healthc. 2013;11:134-9.

[151] Amundsen AL, Ose L, Nenseter MS, Ntanios FY. Plant sterol ester-enriched spread lowers plasma total and LDL cholesterol in children with familial

hypercholesterolemia. Am J Clin Nutr. 2002;76:338-44.

[152] Stefanutti C, Julius U. Lipoprotein apheresis: State of the art and novelties.

Atherosclerosis Supplements. 2013;14:19-27.

[153] Szczepiorkowski ZM, Winters JL, Bandarenko N, Kim HC, Linenberger ML, Marques MB, et al. Guidelines on the use of therapeutic apheresis in clinical practice - Evidence-based approach from the apheresis applications committee of the American Society for Apheresis. J Clin Apheresis. 2010;25:83-177.

[154] Thompson GR. The evidence-base for the efficacy of lipoprotein apheresis in combating cardiovascular disease. Atherosclerosis Supplements. 2013;14:67-70. 
[155] Thompson GR, HEART-UK LDL Apheresis Working Group. Recommendations for the use of LDL apheresis. Atherosclerosis. 2008;198:247-55.

[156] Health Quality Ontario. Low-density lipoprotein apheresis: an evidence-based analysis. Ontario Health Technology Assessment Series. 2007;7:1-101.

[157] Schettler V, Neumann CL, Hulpke-Wette M, Hagenah GC, Schulz EG, Wieland

E. Current view: indications for extracorporeal lipid apheresis treatment. Clinical

Research in Cardiology Supplements. 2012;7:15-9.

[158] Hudgins LC, Kleinman B, Scheuer A, White S, Gordon BR. Long-Term Safety

and Efficacy of Low-Density Lipoprotein Apheresis in Childhood for Homozygous

Familial Hypercholesterolemia. Am J Cardiol. 2008;102:1199-204.

[159] Palcoux J-B, Atassi-Dumont M, Lefevre P, Hequet O, Schlienger J-L, Brignon

$P$, et al. Low-density Lipoprotein Apheresis in Children With Familial

Hypercholesterolemia: Follow-up to 21 Years. Ther Apher Dial. 2008;12:195-201.

[160] Stefanutti C, Lanti A, Di Giacomo S, Mareri M, De Lorenzo F, Landolfo A, et al.

Therapeutic apheresis in low weight patients: technical feasibility, tolerance,

compliance, and risks. Transfus Apher Sci. 2004;31:3-10.

[161] Græsdal A, Bogsrud MP, Holven KB, Nenseter MS, Narverud I, Langslet G, et

al. Apheresis in homozygous familial hypercholesterolemia: the results of a follow-up of all Norwegian patients with homozygous familial hypercholesterolemia. J Clin Lipidol. 2012;6:331-9.

[162] Kolansky DM, Cuchel M, Clark BJ, Paridon S, McCrindle BW, Wiegers SE, et al. Longitudinal evaluation and assessment of cardiovascular disease in patients with homozygous familial hypercholesterolemia. The American Journal of Cardiology. 2008;102:1438-43.

[163] Vogt A, Parhofer KG. The potential of mipomersen, an ApoB synthesis inhibitor, to reduce necessity for LDL-apheresis in patients with heterozygous familial hypercholesterolemia and coronary artery disease. Expert Opin Pharmacother. 2013;14:691-7.

[164] Hovingh GK, Davidson MH, Kastelein JJP, O'Connor AM. Diagnosis and treatment of familial hypercholesterolaemia. Eur Heart J. 2013:[Epub ahead of print]. [165] Wierzbicki AS, Viljoen A, Hardman TC, Mikhailidis DP. New therapies to reduce low-density lipoprotein cholesterol. Curr Opin Cardiol. 2013;28:452-7. [166] Moini M, Mistry P, Schilsky ML. Liver transplantation for inherited metabolic disorders of the liver. Curr Opin Organ Tran. 2010;15:269-76.

[167] Maiorana A, Nobili V, Calandra S, Francalanci P, Bernabei S, El Hachem M, et al. Preemptive liver transplantation in a child with familial hypercholesterolemia.

Pediatr Transplant. 2011;15:E25-E9.

[168] Nemati MH, Astaneh B. Optimal management of familial hypercholesterolemia: treatment and management strategies. Vasc Health Risk Manag. 2010;6:1079 -88.

[169] Ibrahim M, El-Hamamsy I, Barbir M, Yacoub MH. Translational Lessons from a Case of Combined Heart and Liver Transplantation for Familial

Hypercholesterolemia 20 Years Post-operatively. J Cardiovasc Transl Res.

2012;5:351-8.

[170] Buchwald H, Rudser KD, Williams SE, Michalek VN, Vagasky J, Connett JE. Overall Mortality, Incremental Life Expectancy, and Cause of Death at 25 Years in the Program on the Surgical Control of the Hyperlipidemias. Ann Surg.

2010;251:1034-40.

[171] Marais AD, Firth JC, Blom DJ. Homozygous Familial Hypercholesterolemia and Its Management. Semin Vasc Med. 2004;4:43,50. 
[172] Al-Allaf F, Coutelle C, Waddington S, David A, Harbottle R, Themis M. LDLRGene therapy for familial hypercholesterolaemia: problems, progress, and perspectives. Int Arch Med. 2010;3:36.

[173] Kassim SH, Li H, Bell P, Somanathan S, Lagor W, Jacobs F, et al. AdenoAssociated Virus Serotype 8 Gene Therapy Leads to Significant Lowering of Plasma Cholesterol Levels in Humanized Mouse Models of Homozygous and Heterozygous Familial Hypercholesterolemia. Hum Gene Ther. 2013;24:19-26.

[174] Marais AD, Blom DJ. Recent advances in the treatment of homozygous familial hypercholesterolaemia. Curr Opin Lipidol. 2013;24:288-94.

[175] Seidah NG. Proprotein Convertase Subtilisin Kexin 9 (PCSK9) inhibitors in the treatment of hypercholesterolemia and other pathologies. Curr Pharm Des.

2013;19:3161-72.

[176] Stein EA, Gipe D, Bergeron J, Gaudet D, Weiss R, Dufour R, et al. Effect of a monoclonal antibody to PCSK9, REGN727/SAR236553, to reduce low-density lipoprotein cholesterol in patients with heterozygous familial hypercholesterolaemia on stable statin dose with or without ezetimibe therapy: a phase 2 randomised controlled trial. The Lancet. 2012;380:29-36.

[177] McKenney JM, Koren MJ, Kereiakes DJ, Hanotin C, Ferrand A-C, Stein EA. Safety and efficacy of a monoclonal antibody to proprotein convertase subtilisin/kexin type 9 serine protease, SAR236553/REGN727, in patients with primary hypercholesterolemia receiving ongoing stable atorvastatin therapy. J Am Coll Cardiol. 2012;59:2344-53.

[178] Stein EA, Mellis S, Yancopoulos GD, Stahl N, Logan D, Smith WB, et al. Effect of a monoclonal antibody to PCSK9 on LDL cholesterol. N Engl J Med. 2012;366:1108-18.

[179] Raal F, Scott R, Somaratne R, Bridges I, Li G, Wasserman SM, et al. LowDensity Lipoprotein Cholesterol-Lowering Effects of AMG 145, a Monoclonal Antibody to Proprotein Convertase Subtilisin/Kexin Type 9 Serine Protease in Patients With Heterozygous Familial HypercholesterolemiaClinical Perspective The Reduction of LDL-C With PCSK9 Inhibition in Heterozygous Familial Hypercholesterolemia Disorder (RUTHERFORD) Randomized Trial. Circulation. 2012;126:2408-17.

[180] Giugliano RP, Desai NR, Kohli P, Rogers WJ, Somaratne R, Huang F, et al. Efficacy, safety, and tolerability of a monoclonal antibody to proprotein convertase subtilisin/kexin type 9 in combination with a statin in patients with hypercholesterolaemia (LAPLACE-TIMI 57): a randomised, placebo-controlled, dose-ranging, phase 2 study. The Lancet. 2012;380:2007-17.

[181] Koren MJ, Scott R, Kim JB, Knusel B, Liu T, Lei L, et al. Efficacy, safety, and tolerability of a monoclonal antibody to proprotein convertase subtilisin/kexin type 9 as monotherapy in patients with hypercholesterolaemia (MENDEL): a randomised, double-blind, placebo-controlled, phase 2 study. The Lancet. 2012;380:1995-2006. [182] Stein EA, Honarpour N, Wasserman SM, Xu F, Scott R, Raal FJ. Effect of the PCSK9 Monoclonal Antibody, AMG 145, in Homozygous Familial Hypercholesterolemia. Circulation. 2013:[Epud ahead of print]. [183] Visser ME, Witztum JL, Stroes ESG, Kastelein JJP. Antisense oligonucleotides for the treatment of dyslipidaemia. Eur Heart J. 2012;33:1451-8.

[184] Stein EA, Dufour R, Gagne C, Gaudet D, East C, Donovan JM, et al. Apolipoprotein B Synthesis Inhibition With Mipomersen in Heterozygous Familial HypercholesterolemiaClinical Perspective Results of a Randomized, Double-Blind, 
Placebo-Controlled Trial to Assess Efficacy and Safety as Add-On Therapy in Patients With Coronary Artery Disease. Circulation. 2012;126:2283-92.

[185] McGowan MP, Tardif J-C, Ceska R, Burgess LJ, Soran H, Gouni-Berthold I, et al. Randomized, placebo-controlled trial of mipomersen in patients with severe hypercholesterolemia receiving maximally tolerated lipid-lowering therapy. PLoS ONE. 2012;7:e49006.

[186] Cuchel M, Rader DJ. Microsomal transfer protein inhibition in humans. Curr Opin Lipidol. 2013;24:246-50.

[187] Sullivan D, Olsson AG, Scott R, Kim JB, Xue A, Gebski V, et al. Effect of a Monoclonal Antibody to PCSK9 on Low-Density Lipoprotein Cholesterol Levels in Statin-Intolerant PatientsThe GAUSS Randomized TrialAMG145 in Statin-Intolerant Patients. JAMA. 2012;308:2497-506.

[188] Avis HJ, Kusters DM, Vissers MN, Huijgen R, Janssen TH, Wiegman A, et al. Follow-up of children diagnosed with familial hypercholesterolemia in a national genetic screening program. The Journal of Pediatrics. 2012;161:99-103.

[189] Hadfield SG, Horara S, Starr BJ, Yazdgerdi S, Bhatnagar D, Cramb R, et al. Are patients with familial hypercholesterolaemia well managed in lipid clinics? An audit of eleven clinics from the Department of Health Familial Hypercholesterolaemia Cascade Testing project. Ann Clin Biochem. 2008;45:199-205.

[190] Pedersen KMV, Humphries SE, Roughton M, Besford JS. The National Audit of the Management of Familial Hypercholesterolaemia 2010: Full report. Clinical Standards Department, Royal College of Physicians2010.

[191] Goldberg AC, Robinson JG, Cromwell WC, Ross JL, Ziajka PE. Future issues, public policy, and public awareness of Familial Hypercholesterolemias:

Recommendations from the National Lipid Association Expert Panel on Familial Hypercholesterolemia. J Clin Lipidol. 2011;5:S46-S51.

[192] Aarden E, Van Hoyweghen I, Horstman K. The paradox of public health genomics: Definition and diagnosis of familial hypercholesterolaemia in three European countries. Scand J Public Health. 2011;39:634-9.

[193] Mata N, Alonso R, Badimón L, Padró T, Fuentes F, Muñiz O, et al. Clinical characteristics and evaluation of LDL-cholesterol treatment of the Spanish Familial Hypercholesterolemia Longitudinal Cohort Study (SAFEHEART). Lipids Health Dis. 2011;10:94.

[194] Bairey Merz CN, Alberts MJ, Balady GJ, Ballantyne CM, Berra K, Black HR, et al. ACCF/AHA/ACP 2009 Competence and Training Statement: A Curriculum on Prevention of Cardiovascular Disease. J Am Coll Cardiol. 2009;54:1336-63.

[195] Mata N, Alonso R, Banegas JR, Zambon D, Brea A, Mata P. Quality of life in a cohort of familial hypercholesterolemia patients from the south of Europe. Eur $\mathrm{J}$ Public Health. 2012:[Epud ahead of print].

[196] Bell DA, Garton-Smith J, Vickery A, Kirke A, Pang J, Bates TR, et al. Familial Hypercholesterolaemia in Primary Care: Knowledge and Practices Among General Practitioners in Western Australia. Heart Lung Circ. 2013:[Epub ahead of print]. [197] Stephenson SH, Larrinaga-Shum S, Hopkins PN. Benefits of the MEDPED treatment support program for patients with familial hypercholesterolemia. J Clin Lipidol. 2009;3:94-100.

[198] Allen JK, Himmelfarb CRD, Szanton SL, Frick KD. Cost-effectiveness of Nurse Practitioner/Community Health Worker Care to Reduce Cardiovascular Health Disparities. The Journal of Cardiovascular Nursing. 2013:[Epub ahead of print]. [199] Ross J. Educating Patients About Familial Hypercholesterolemia: The Role of the Cardiovascular Nurse. J Cardiovasc Nurs. 2013;28:102. 
[200] Maron DJ, Boden WE, Weintraub WS, O'Rourke RA. Is optimal medical therapy as used in the Courage Trial feasible for widespread use? Curr Treat Options Cardiovasc Med. 2011;13:16-25.

[201] Aatre RD, Day SM. Psychological Issues in Genetic Testing for Inherited Cardiovascular Diseases. Circulation: Cardiovascular Genetics. 2011;4:81-90. [202] Krass I, Walker AT, Watts GF. Detection and care of familial hypercholesterolaemia in the community: is there a role for the pharmacist? International Journal of Clinical Pharmacy. 2012;34:501-5. [203] Watts GF, Sullivan DR, van Bockxmeer FM, Poplawski N, Hamilton-Craig I, Clifton PM, et al. A new model of care for familial hypercholesterolaemia: What is the role of cardiology? Heart Lung Circ. 2012;21:543-50.

[204] Califf RM, Peterson ED, Gibbons RJ, Garson A, Brindis RG, Beller GA, et al. Integrating quality into the cycle of therapeutic development. J Am Coll Cardiol. 2002;40:1895-901. 